\title{
Estimates of twenty-first century sea-level changes for Norway
}

\author{
Matthew J. R. Simpson • Kristian Breili • \\ Halfdan P. Kierulf
}

Received: 31 October 2012/Accepted: 30 July 2013/Published online: 11 August 2013

(c) The Author(s) 2014. This article is published with open access at Springerlink.com

\begin{abstract}
In this work we establish a framework for estimating future regional sea-level changes for Norway. Following recently published works, we consider how different physical processes drive non-uniform sea-level changes by accounting for spatial variations in (1) ocean density and circulation (2) ice and ocean mass changes and associated gravitational effects on sea level and (3) vertical land motion arising from past surface loading change and associated gravitational effects on sea level. An important component of past and present sea-level change in Norway is glacial isostatic adjustment. Central to our study, therefore, is a reassessment of vertical land motion using a far larger set of new observations from a permanent GNSS network. Our twenty-first century sea-level estimates are split into two parts. Firstly, we show regional projections largely based on findings from the Fourth Assessment Report of the Intergovernmental Panel on Climate Change (IPCC AR4) and dependent on the emission scenarios A2, $\mathrm{A} 1 \mathrm{~B}$ and $\mathrm{B} 1$. These indicate that twenty-first century relative sea-level changes in Norway will vary between -0.2 to $0.3 \mathrm{~m}$ (1-sigma $\pm 0.13 \mathrm{~m}$ ). Secondly, we explore a high-end scenario, in which a global atmospheric temperature rise of up to $6{ }^{\circ} \mathrm{C}$ and emerging collapse for some areas of the Antarctic ice sheets are assumed. Using this approach twenty-first century relative sea-level changes in Norway are found to vary between 0.25 and $0.85 \mathrm{~m}(\mathrm{~min} /$ $\max \pm 0.45 \mathrm{~m})$. We attach no likelihood to any of our
\end{abstract}

M. J. R. Simpson $(\bowtie) \cdot$ K. Breili · H. P. Kierulf

Geodetic Institute, Norwegian Mapping Authority,

Hønefoss, Norway

e-mail: Matthew.Simpson@kartverket.no

H. P. Kierulf

Department of Geosciences, University of Oslo, Oslo, Norway projections owing to the lack of understanding of some of the processes that cause sea-level change.

Keywords Sea-level projections · Glacial isostatic adjustment $\cdot$ Norway

\section{Introduction}

There is large uncertainty associated with projections of twenty-first century global sea-level change. This uncertainty is due to a lack of understanding of some of the processes that drive sea-level changes and, in particular, the potential contributions of the large ice sheets. Projections given in the Fourth Assessment Report from the Intergovernmental Panel on Climate Change (hereafter IPCC AR4) indicate a global mean sea-level rise of 0.18-0.76 $\mathrm{m}$ for the period 2090-2099 relative to 1980-1999 (Meehl et al. 2007). (Note that these projections include the so called scaled-up values for future icedynamic changes). Given limited understanding of the causes of sea-level change, however, neither an upper bound nor probability was attached to the IPCC AR4 projections. Clearly, an inability to assign probabilities to sea-level projections is not a problem confined to the IPCC AR4, it is a long standing issue in sea level science which the community is working to address. This issue, in turn, has presented a difficulty for coastal planners and other decision makers as, for a quantitative risk assessment, information on future sea levels is required in a probabilistic form (Pfeffer 2011).

Following the IPCC AR4, significant progress has been made in sea level research (e.g. Cazenave et al. 2009; Milne et al. 2009; Church et al. 2011) and efforts are underway to improve projections of the contributions of ice 
to future sea-level change (e.g. www.ice2sea.eu). Nevertheless, reliable sea-level projections are likely still some years away. Over the same period, there has also been an increased interest in regional and/or local projections of sea-level change (e.g. Katsman et al. 2008, 2011; Kopp et al. 2010; Church et al. 2011; Slangen et al. 2012). Observations show that past sea-level changes have been spatially variable (or non-uniform), so we expect that future changes will also be of this nature (Milne et al., 2009). Thus, identifying the processes causing sea-level changes at regional scales (e.g. Landerer et al. 2007; Pardaens et al. 2011) and improving future projections of the spatial variability of sea-level change (e.g. Gomez et al. 2010) have become an important focus for scientific researchers. The move towards regional projections has also led to several countries commissioning national reports into future sea-level changes. For example, the Delta Committee report for the Netherlands (Vellinga et al. 2008) and the United Kingdom's climate projections (Lowe et al. 2009). In this vein, we present here a framework for assessing future sea-level changes for Norway. The main aim of this work is to show how twenty-first century regional sea-level changes will affect the Norwegian coast.

Relative Sea-Level (RSL) change is defined as the change in ocean surface height with respect to the solid Earth. Paleo observations from across Fennoscandia, including Norway, show a spatial pattern of RSL change over the past $\sim 10,000$ years that largely reflects vertical land motion (e.g. Lambeck et al. 1998). This process, termed Glacial Isostatic Adjustment (GIA), provides a measure of the Earth's viscous relaxation in response to past ice mass loss. As well as being evident in the paleo record, analyses of the Fennoscandian tide-gauge network also show that GIA is an important component of twentieth century RSL change (e.g. Ekman 1996; Henry et al. 2012; Richter et al. 2012). These tide-gauge data, which are unevenly spaced along the coast, indicate that over the past $\sim 100$ years some areas of Norway experienced an overall RSL fall while other areas underwent a limited RSL rise (that is, values somewhat below the global mean). More recently, the advent of Global Navigation Satellite Systems (GNSS) and other geodetic techniques have enabled us to directly measure present-day crustal deformation and to do so with a high degree of precision (e.g. Milne et al. 2001; Johansson et al. 2002). These geodetic data show that, generally speaking, highest rates of uplift correspond to areas of thickest ice during the last glacial. In summary, a range of observations show that vertical land motion needs to be carefully considered if we are to arrive at accurate sea-level projections for Norway.

Changes in RSL due to deflections of the ocean surface can arise due to a number of different physical processes.
In our analysis, closely following methods in recently published works (Katsman et al. 2011; Slangen et al. 2012), we focus on non-uniform ocean surface height changes arising from variations in (1) ocean mass and (2) ocean density and circulation. Changes in ocean mass (here we consider only the exchange of mass between ice reservoirs and the oceans) will produce a non-uniform sea level pattern largely owing to self-gravitational effects of the ice load. This sea level response is often referred to as a 'fingerprint' as it can be used to identify the source and size of ice mass variations. While the formalization of this theory has been established for several decades (Farrell and Clark 1976) it is not until recently that concerted efforts have been made to include non-uniform ocean mass changes into projections (e.g. Mitrovica et al. 2009; Gomez et al. 2010). This reluctance is partly due to an inability to well constrain the future contributions of the large ice sheets.

Changes in ocean density and circulation can be divided up as follows: Firstly, if we consider ocean density changes (also known as the steric signal), non-uniform ocean surface changes are caused by regional variations in ocean temperature and salinity-the thermosteric and halosteric signals, respectively. Secondly, for ocean circulation (the redistribution of ocean mass), non-uniform ocean surface changes are driven by variations in ocean density and wind stress. Projections from climate models show that nonuniform ocean surface changes mainly relate to the ocean density signal (e.g. Lowe and Gregory 2006). It is important to note that results from different climate models also show that there is little agreement between projected patterns of ocean surface variations (e.g. Gregory et al. 2001; Meehl et al. 2007). This means there is generally low confidence in regional projections of ocean density and circulation change. Both regional projections of non-uniform ocean surface changes owing to variations in (1) ocean mass (land ice) and (2) ocean density and circulation, therefore, suffer from relatively large uncertainties.

The paper is structured as follows: In Sect. 2 we examine vertical land motion in Norway, which we constrain using new GNSS observations (Kierulf et al. 2013) and a forward model of GIA. Our projections of twentyfirst century RSL change are split into two parts. Firstly, in Sects. 3.1 to 3.2 we present projections largely based on the findings of the IPCC AR4 and from Slangen et al. (2012). In the second part (Sect. 3.3), we explore a high-end scenario in which a global atmospheric temperature rise of up to $6{ }^{\circ} \mathrm{C}$ and emerging collapse for some areas of the Antarctic ice sheets are assumed (Katsman et al. 2011). The discussion is given in Sect. 4, where we briefly compare our projections to present-day observations of RSL change from the Norwegian tide gauge network. We go on to consider the largest uncertainties associated with our projections and processes that drive sea-level changes but are 
not included in this study. The conclusions are listed in Sect. 5.

\section{Present-day vertical land motion in Norway}

Observations of GIA in Fennoscandia have traditionally been used to infer details of Earth's viscosity structure and/ or the region's ice history (e.g. Fjeldskaar 1994; Lambeck et al. 1998; Milne et al. 2001; Steffen and Kaufmann 2005). They also inform us on vertical land motion-an important component of present-day RSL change for Norway. In this Section we use new GNSS observations (Kierulf et al. 2013) to investigate present-day vertical land motion. We focus on the vertical component of motion as it is this, rather than horizontal movements, which is most useful for estimating present and future sea-level changes. Using the new GNSS observations we use a forward model of GIA to determine a crustal velocity field for Norway (see also Kierulf et al. 2013).

\subsection{Observations of vertical land motion in Norway}

In a landmark project named BIFROST (Baseline Inferences for Fennoscandian Rebound Observations Sea Level and Tectonics), a network of GNSS observations from across Fennoscandia was used to investigate regional present-day crustal motion (Milne et al. 2001; Johansson et al. 2002). These studies included measurements from the GNSS networks in Sweden and Finland but data from only 1 GNSS site in Norway (Troms $\varnothing$ ). Since the early 2000s, members of the BIFROST project have continued to update their results and incorporate new GNSS observations into their analyses (Lidberg et al. 2007, 2010). Around 10 GNSS records from Norway are included in the latest work of Lidberg et al. (2010). In a very recent study, Kierulf et al. (2013) examined data from the entire Norwegian GNSS network, which is currently comprised of $\sim 140$ permanent stations (Fig. 1). However, only around half of these sites have been operating for a sufficiently long time that reliable velocity estimates can be determined from the data (see Kierulf et al. 2013) and below). In the following, we briefly outline the analysis and new results of Kierulf et al. (2013), which are a key component of our sea-level projections.

\subsubsection{GNSS analysis-strategy and assessing vertical velocities}

Kierulf et al. (2013) examine GNSS data up until the beginning of 2011 and, for their analysis, employ the GAMIT software (Herring et al. 2010). GAMIT makes use of the so called double difference approach, in which, a

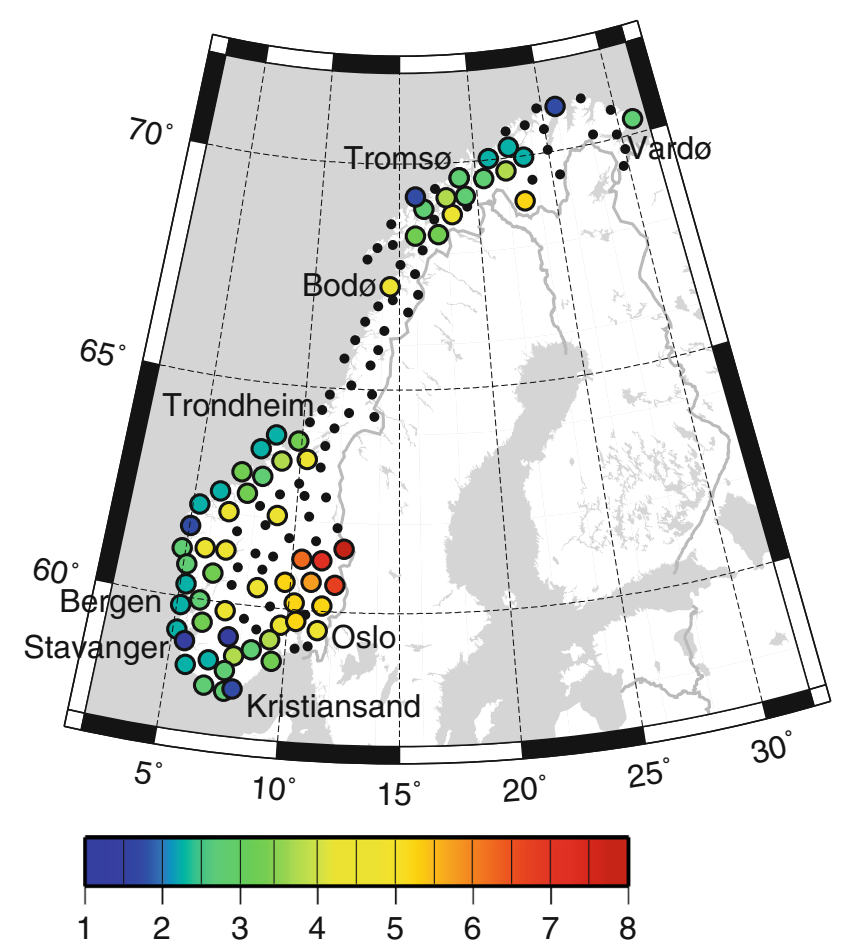

Fig. 1 Locations of the 139 permanent GNSS stations on the Norwegian mainland. Colors indicate estimated vertical velocities ( $\mathrm{mm} /$ year) given in the ITRF2008 reference frame. Dots mark stations with less than 3 years of data; these observations are not included in this study as they are considered unreliable (see also Kierulf et al. 2013)

network of GNSS stations are analyzed in a single adjustment. Note that solutions are given in the ITRF2008 reference frame. The time-series analysis was performed using the CATS software (Williams 2008), using a combination of flicker noise and white noise, as recommended for most GNSS sites (Williams et al. 2004). Annual and semi-annual signals are included as additional parameters in determining the vertical velocity estimates. For more details on the analysis-strategy, see Kierulf et al. (2013).

As the Norwegian GNSS network has been gradually built up over a number of years, some GNSS sites have longer time-series than others. This has implications for the reliability of crustal velocities estimated from GNSS observations in different parts of the network. We note that Kierulf et al. (2013) conduct several tests to show how the stability and uncertainty of the velocity estimates varies as a function of time-series length. In their uncertainty test, for example, they find that velocities derived from 3 years of data have an average uncertainty of $1 \mathrm{~mm} /$ year. For comparison, to achieve an average uncertainty of $0.5 \mathrm{~mm} /$ year requires an observation period of at least 7.5 years. Based on the results of Kierulf et al. (2013) and to ensure our vertical velocity estimates are reliable, we opt to only include data from GNSS stations that have been operating 
for 3 years or longer. Of the 139 stations established in Norway, 66 have been operating for 3 years or more (Fig. 1). This means we currently lack reliable GNSS observations for the middle of Norway (the coast north of Trondheim and south of Bodø) and some coastal areas in the north.

The GNSS observations indicate that vertical land motion over Norway varies between 1 and $8 \mathrm{~mm} /$ year. Coastal locations generally have uplift rates lower than $5 \mathrm{~mm} /$ year (Fig. 1). Note that the average uncertainty on the 66 velocity estimates is $\pm 0.7 \mathrm{~mm} /$ year (Kierulf et al. 2013). In Table 1 we compare the observations reported by Kierulf et al. (2013) to vertical velocities obtained from four earlier GNSS analyses, each study employed a different analysis strategy. Some of the differences between the velocity estimates will be due to different reference frame realizations. For example, Kierulf et al. (2009) show differences of $\sim 1 \mathrm{~mm} /$ year in the vertical component between the ITRF2000 and ITRF2005 realizations over Fennoscandia (ITRF2008 shows negligible differences to ITRF2005). Comparisons between ITRF2000 and ITRF2008 indicate the latter to be the far more precise solution (Altamimi et al. 2011). Thus, we have more confidence in the vertical velocities presented by Kierulf et al. (2013) but note that ITRF2008 will still contain uncertainties.

\subsection{Glacial isostatic adjustment modeling}

The GIA model employed is composed of three components: a model of grounded past ice evolution (for Fennoscandia and other ice covered areas), a sea level model to compute the redistribution of ocean mass for a given ice and Earth model, and an Earth model to compute the solid Earth deformation associated with the ice-ocean loading history. In the following we describe each component in order; the model setup is similar to that used in the analysis of Milne et al. (2001) and Milne et al. (2004).

The ice model is made of two parts: The Fennoscandian and Barents Sea ice sheets are represented by the model of Lambeck et al. (1998), which has been shown to provide good fit to paleo sea level data from the region. For other areas of the globe, we use the ICE-3G ice sheet reconstruction of Tushingham and Peltier (1991).
The sea level model predicts the vertical deflection of both the ocean surface and the Earth's solid surface due to changes in ice-ocean mass configuration. Height shifts of the ocean surface are determined by computing perturbations to the geopotential. Perturbations to the rotation vector and the resulting feedback of this forcing on sea level and land motion are computed as described by Milne and Mitrovica (1998) and Mitrovica et al. (2001a). Global ice/water mass is conserved in the model. For more detail on the sea level algorithm used to compute the ocean loading in this analysis, see Mitrovica and Milne (2003) and Kendall et al. (2005). Note that the sea level model is also applied later in our study to examine the non-uniform sea level response to future ice mass changes (see Sect. 3.1.3).

Following Peltier (1974), the GIA ice-ocean forcings are convolved in space and time with the impulse response Love numbers to give the solution for a generalized surface load. A Maxwell viscoelastic rheology is used and the Earth model is spherically symmetric, self-gravitating and compressible. The elastic and density structure are taken from seismic constraints (Dziewonski and Anderson, 1981) and depth parameterized with a resolution of $15-25 \mathrm{~km}$. The radial viscosity structure is depth parameterized more crudely into three layers: an elastic lithosphere (i.e. very high viscosity values are assigned), an isoviscous upper mantle bounded by the base of the lithosphere and the $670 \mathrm{~km}$ deep seismic discontinuity, and an isoviscous lower mantle continuing below this depth to the coremantle boundary.

To compute present-day vertical land motion, we adopted an algorithm based on that described by Mitrovica et al. (1994). Spherical harmonic expansions were truncated at degree and order 256.

\subsubsection{Earth model sensitivity test and determining a best-fit model}

Past GIA modeling studies have used both paleo sea level data (e.g. Lambeck et al. 1998) and/or GNSS observations (e.g. Milne et al. 2001, 2004) to help constrain Earth model parameters. These investigations have shown that it is not yet possible to uniquely constrain Earth's viscosity structure for the Fennoscandian region. Such studies, however,

Table 1 Estimated vertical velocities (mm/year) obtained in different analyses for 5 of the Norwegian GNSS stations

\begin{tabular}{|c|c|c|c|c|c|}
\hline & Oslo & Stavanger & Trondheim & Troms $\varnothing$ & Vard $\varnothing$ \\
\hline Johanssen et al. (2002) & - & - & - & 4 & - \\
\hline Lidberg et al. (2007) ITRF2000 & 5.8 & 1.2 & 3.8 & 2.3 & 1.9 \\
\hline Lidberg et al. (2010) ITRF2005 & 6.5 & 2.9 & 6.2 & 4.6 & 5.7 \\
\hline Kierulf et al (2013) ITRF2008 & 5.1 & 1.5 & 4.3 & 2.9 & 2.7 \\
\hline
\end{tabular}


are able to provide a range of Earth parameter values that satisfy the various GIA observables. Given our limited knowledge of Earth's viscosity structure, we generate predictions of present-day vertical land motion using a suite of 297 Earth viscosity models. The range of values we explore is similar to those in Milne et al. (2001, 2004), namely; lithospheric thickness is varied from 71 to $120 \mathrm{~km}$, upper mantle viscosity from $0.05 \times 10^{21}$ to $5 \times 10^{21}$ Pas and lower mantle viscosity from $10^{21}$ to $50 \times 10^{21}$ Pas.

To determine an optimal Earth model (i.e. the model which gives best-fit to the GNSS data) we conduct a simple statistical test. We compute vertical velocities at all 66 GNSS stations considered for each of the 297 Earth models introduced above and quantify the goodness of fit for each Earth model using the $\chi^{2}$ criterion:

$\chi^{2}=\frac{1}{n} \sum_{i=1}^{n}\left(\frac{y_{i}^{\text {pred }}-y_{i}^{\text {obs }}}{\sigma_{i}}\right)^{2}$

The $\chi^{2}$ value indicates the difference between the predicted $\left(y_{i}^{\text {pred }}\right)$ and observed vertical velocity $\left(y_{i}^{\text {obs }}\right)$ for a specified observational error $\left(\sigma_{i}\right)$ and given GNSS station (i). A value of 1 or less indicates fit to the data.

Figure 2 shows how goodness of fit to the GNSS observations varies with Earth model parameters. We find similar results to Milne et al. $(2001,2004)$, namely that the vertical velocities favor an Earth model with a relatively stiff upper mantle. Differences between $\chi^{2}$ values for the various lithospheric thicknesses are small. Results from a more comprehensive investigation, however, suggest a preference for a lithosphere of $\sim 100 \mathrm{~km}$ or thicker (Milne et al. 2004). For the models with a $120 \mathrm{~km}$ lithospheric thickness, an upper mantle viscosity of $3 \times 10^{21}$ Pas and lower mantle viscosity of $5 \times 10^{21}$ Pas gives best-fit to the GNSS data. In the remainder of this analysis, we only use predictions from this model (hereafter referred to as our best-fit GIA model).

As discussed above, the vertical component of motion is most important when considering sea-level changes. The intent of the GIA modeling work performed here is, therefore, to find a land motion model that best fits the observed vertical velocities, rather than as an investigation of past ice mass changes and/or Earth viscosity structure. We note that other studies have inferred Earth viscosity values differing to ours and indicate significant lateral variations of Earth structure across Fennoscandia (see the in-depth review of Steffen and Wu (2011)). Indeed, lateral variations in Earth structure must be included if GNSS observations are to be interpreted correctly for studies of GIA (Whitehouse et al. 2006), but this goes somewhat beyond the scope of our work here.

\subsubsection{Modeled vertical land motion and associated gravitational effects on sea level}

Predicted vertical velocities generated using our best-fit GIA model (Fig. 3) show a pattern of land motion similar to previous work (e.g. Milne et al. 2001; Hill et al. 2010). All of mainland Norway is predicted to be uplifting; rates along the Norwegian coast vary between 1 and $5 \mathrm{~mm} /$ year. Residuals between the best-fit GIA model and GNSS data show that the model tends to slightly over predict rates of uplift in the middle of Norway, around $64^{\circ} \mathrm{N}$, and under predict towards the south (Fig. 3). However, no clear pattern of misfit is apparent. At 39 of the 66 GNSS stations examined, differences between the modeled and observed vertical velocities are less than the uncertainty on the observed value (i.e. at these positions $\chi^{2}$ is less than 1 and the model provides a good fit to the GNSS data). In
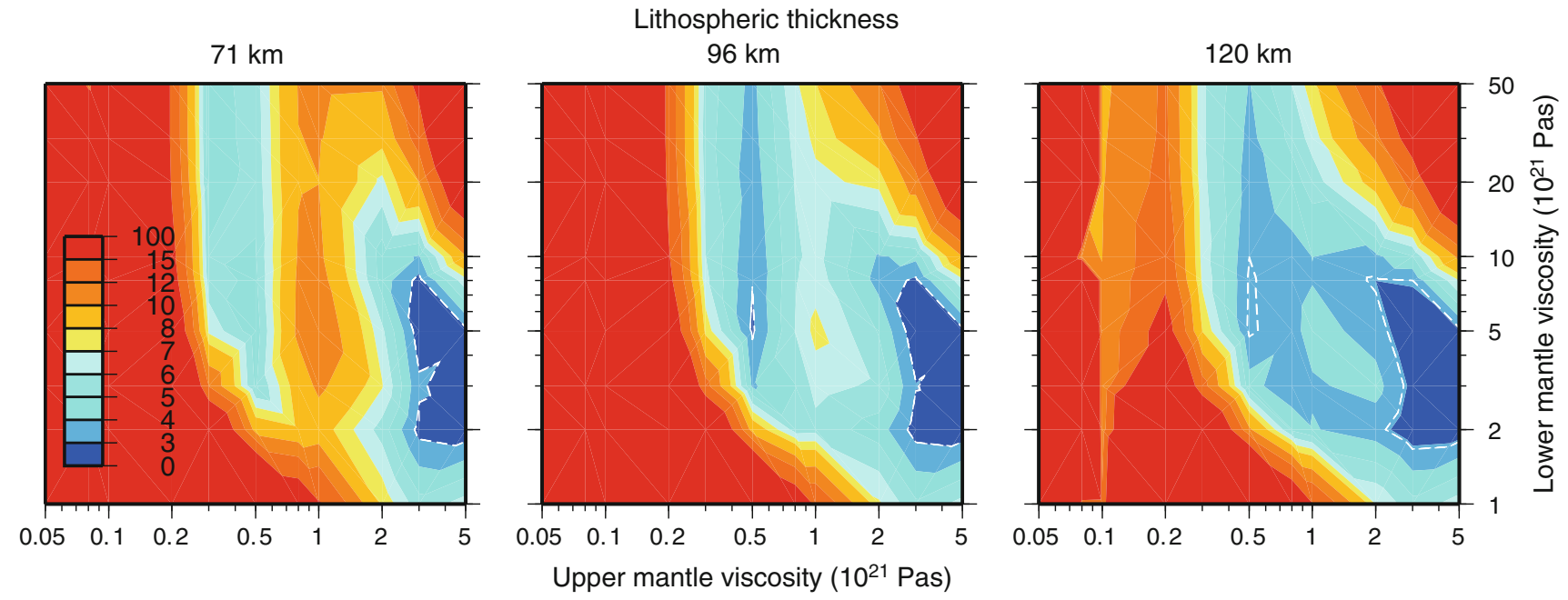

Fig. 2 The $\chi^{2}$ results for 297 different Earth viscosity models (see text for details). Each frame is based on a fixed value for lithospheric thickness. The $95 \%$ confidence level is marked by the white dashed line 
summary, the GIA model fits the majority of the data but there are noticeable misfits in some locations. For areas where we do not have reliable GNSS data, however, the GIA model provides a useful tool for estimating vertical land motion (see also Kierulf et al. 2013).

We also take into account gravitational effects on sea level associated with GIA. These ocean surface height changes are typically between 5 and $10 \%$ of the vertical land motion signal (Tamisiea and Mitrovica 2011) so this is a relatively small effect. The predicted ocean surface height changes generated using our best-fit GIA model show a pattern similar to our predicted vertical velocities (figure not shown). Maximum rates at the centre of uplift are around $0.6 \mathrm{~mm} /$ year, this is slightly larger than the $0.4 \pm 0.1 \mathrm{~mm} /$ year found by Milne et al. (2001) although there are differences in our model setup. (Note that using a similar range of Earth model parameters as we explore here, Milne et al. (2001) show the sensitivity of ocean surface changes associated with GIA to variations in Earth viscosity structure is no larger than $\pm 0.1 \mathrm{~mm} /$ year). For our best-fit GIA model, we find ocean surface changes associated with GIA vary between 0.2 and $0.5 \mathrm{~mm} /$ year along the Norwegian coast.

\subsubsection{Uncertainties in the modeled vertical land motion field}

We estimate the uncertainty of the best-fit GIA model velocity solutions as $0.5 \mathrm{~mm} /$ year (1-sigma). This is the

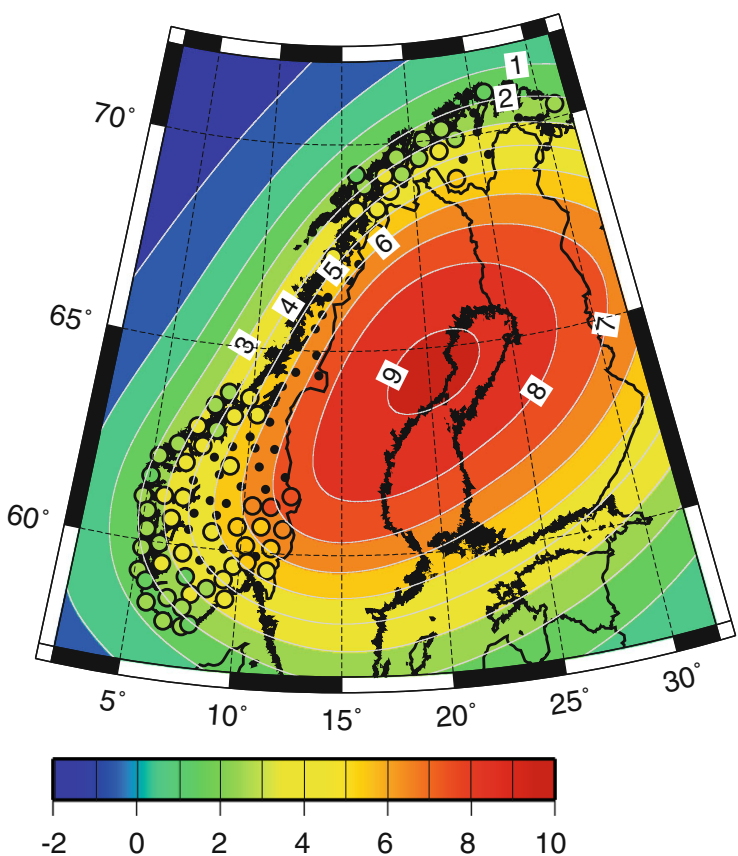

Fig. 3 Predicted vertical velocities (mm/year) for Fennoscandia using our best-fit GIA model (left). Observed vertical velocities are also shown as in Fig. 1. Residuals; observed vertical velocities minus our best-fit GIA model prediction for the 66 GNSS stations examined
RMS of the differences between velocities from the model and all the GNSS observations but with some outliers removed (see Kierulf et al. 2013). As mentioned, our vertical velocity solutions are constrained by observations in the ITRF2008 reference frame, which also has uncertainties (Altamimi et al. 2011; Wu et al. 2011). The uncertainties in geocenter motion and scale of the reference frame are important for the vertical velocity estimates and, consequently, our regional sea-level projections (see Table 1). Reference frame uncertainties are hard to quantify due to lack of independent measurements. Recent work by $\mathrm{Wu}$ et al. (2011), however, presents an estimate of these uncertainties by combining data from GRACE, ocean bottom pressure measurements and ITRF2008 results. They find the geocenter of ITRF2008 is consistent with the center of mass of the Earth at $0.5 \mathrm{~mm} /$ year and that the accuracy of the scale of the reference frame is $0.2 \mathrm{~mm} /$ year. We, therefore, estimate the total uncertainty of our crustal velocity field as $\sqrt{0.5^{2}+0.5^{2}+0.2^{2}}=0.7 \mathrm{~mm} /$ year (1-sigma).

\section{Projected twenty-first century relative sea-level changes}

Here we present our projections of twenty-first century RSL change for Norway. In the first part of our analysis (Sects. 3.1-3.2), we use methods and results from IPCC

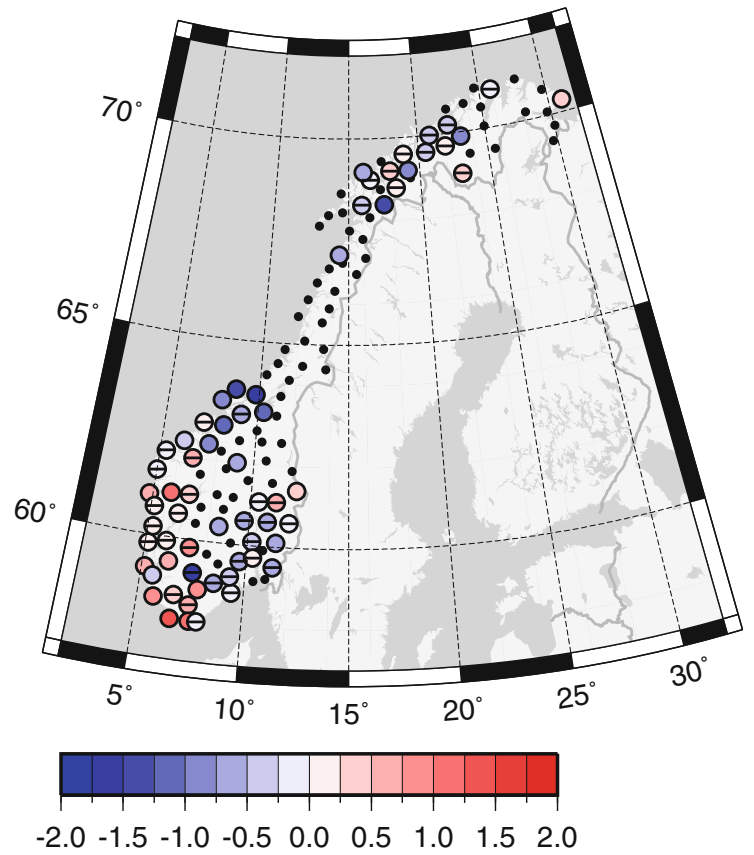

(right). Circles with a horizontal line through have a residual value less than the uncertainty of the observed velocity (i.e. a $\chi^{2}$ value of 1 or less) 
AR4 and Slangen et al. (2012) to calculate regional RSL changes using output from models forced by the SRES scenarios A2, A1B and B1 (Nakicenovic and Swart 2000). We consider how different processes drive non-uniform RSL changes by accounting for variations in (1) ocean density and circulation (2) ice and ocean mass and associated gravitational effects and (3) vertical land motion arising from past surface loading change and associated gravitational effects on sea level (see Sect. 2). This is a useful exercise as it shows, in more detail than previous works, how global projections largely from IPCC AR4 are different along the Norwegian coast when regional RSL variations are taken into account.

In the second part of our analysis (Sect. 3.3), we explore a high-end scenario of twenty-first century RSL changes for Norway. There are two motivations for doing this: Firstly, maximum global atmospheric temperature rise for the scenarios A2, A1B and B1 is projected to be not much larger than $\sim 4{ }^{\circ} \mathrm{C}$ (Meehl et al. 2007). Hence, none of these scenarios are considered to be high-end scenarios of climate change. For computing ocean density and circulation changes, therefore, we explore the scenario of up to a $6{ }^{\circ} \mathrm{C}$ warming (Katsman et al. 2008, 2011). Secondly, there are large uncertainties associated with the potential contributions of the ice sheets, and to a lesser extent, glaciers and ice caps. High-end ocean mass changes are estimated using the assumption that observed present-trends of ice loss (accelerations) continue and/or using expert judgment (Meier et al. 2007; Katsman et al. 2011).

\subsection{Data and model descriptions}

We make use of results from Atmosphere Ocean General Circulation Models (AOGCMs) which are available in the Coupled Model Intercomparison Project phase 3 (CMIP3) database. As in Slangen et al. (2012), we examine output from models forced by the IPCC SRES scenarios A2, A1B and B1. To calculate regional sea-level projections requires several model outputs. This information, however, is not available for all of the AOGCMs in the CMIP3 database.

\subsubsection{Future ocean density and circulation changes}

To calculate regional future ocean density and circulation changes requires (1) the projected global mean, which can be approximated as the global mean thermal expansion as global salinity changes are so small, and (2) the local deviation with respect to the global mean. The latter is known as the Dynamic Sea Level (DSL) and is related to regional variations in ocean temperature and salinity and circulation changes. Non-uniform ocean surface changes owing to density and circulation changes $(\Delta H(\theta, \phi, t))$ are given as (Yin et al. 2010):
$\Delta H(\theta, \phi, t)=\Delta D S L(\theta, \phi, t)+\Delta h(t)$

Thus, local sea-level change consists of the change in the global mean thermal expansion $(\Delta h(t))$ plus the change in dynamic sea level $(\Delta D S L(\theta, \phi, t))$. Projections are a function of $(\theta)$ latitude and $(\phi)$ longitude and $(t)$ time. Note that the global mean thermal expansion component has been corrected for the near linear trend found in some of the AOGCMs control runs (e.g. Gregory et al. 2001). As information is not available for all the AOGCMs, we use between 12 and 15 of the models in the CMIP3 database to calculate the projected global mean depending on the forcing scenario applied.

Table 2 lists the 17 AOGCMs from which we examine future ocean density and circulation changes. Before computing twenty-first century local DSL changes, however, we perform a regional assessment of the AOGCMs. In this test, we examine the ability of the models to replicate present-day observed DSL for the period 1992-2002. If the models are able to adequately reproduce present-day regional patterns of DSL, then it gives us increased confidence in their suitability for projecting twenty-first century sea-level changes for the Norwegian coast (e.g. Yin et al. 2010; Slangen et al. 2012).

We follow a similar methodology as described by Yin et al. (2010). The observed DSL from 1992 to 2002 is obtained from altimetry data and drifting buoys

Table 2 The 17 AOGCMs used to calculate regional ocean density and circulation changes

\begin{tabular}{lll}
\hline Model & Scenarios & Reference \\
\hline BCCR BCM 2.0 & A1B, A2, B1 & Furevik et al. (2003) \\
CCCMA CGCM 3.1* & A1B, A2, B1 & Flato (2005) \\
GFDL CM 2.0 & A1B, A2 & Delworth et al. (2006) \\
GFDL CM 2.1 & A1B, A2, B1 & Delworth et al. (2006) \\
GISS AOM* & A1B, B1 & Lucarini and Russell (2002) \\
GISS MODEL EH* & A1B & Schmidt et al. (2006) \\
GISS MODEL ER* & A1B, A2, B1, & Schmidt et al. (2006) \\
IAP FGOALS 1.0 g & A1B, B1 & Yongqiang et al. (2002) \\
MIROC 3.2 (hires) & A1B, B1 & Hasumi and Emori (2004) \\
MIROC 3.2 (medres) & A2, B1 & Hasumi and Emori (2004) \\
MIUB ECHO-g* & A1B, A2, B1 & Min et al. (2005) \\
MPI ECHAM5 & A1B, A2, B1 & Jungclaus et al. (2006) \\
MRI CGCM 2.3.2a* & A1B, A2, B1 & Yukimoto and Noda (2002) \\
NCAR CCSM 3.0 & A1B, A2, B1 & Collins et al. (2006) \\
NCAR PCM 1 & A1B, A2, B1 & Washington et al. (2000) \\
UKMO HADCM 3 & A1B, A2, B1 & Gordon et al. (2000) \\
UKMO HADGEM & A1B, A2 & Johns et al. (2006) \\
\hline
\end{tabular}

* Models omitted from further analysis because they show poor agreement to the observed dynamic sea level and/or include a contribution from land ice that cannot be separated from the steric signal (see Sect. 3.1.1) 
(Maximenko et al. 2009; Niiler et al. 2003). In order to make a comparison, modeled DSL changes were averaged over the same period. We select two rectangular windows to make our regional assessment; the areas $0-14^{\circ} \mathrm{E}, 56-$ $66^{\circ} \mathrm{N}$ and $0-34^{\circ} \mathrm{E}, 66-73^{\circ} \mathrm{N}$. Note that this study area excludes all data in the Gulf of Bothnia. Differences between models $\left(D S L_{i}^{\text {mod }}\right)$ and observations $\left(D S L_{i}^{o b s}\right)$ were calculated by computing the RMS error (Yin et al. 2010):

$R M S^{2}=\frac{1}{W} \sum_{i}^{N} w_{i}\left(D S L_{i}^{m o d}-D S L_{i}^{o b s}\right)^{2}$

In Eq. 3 the weight of the grid-point $\left(w_{i}\right)$ is set equal to the area of the corresponding grid-cell and the sum of the weights $(W)$ corresponds to the total ocean area covered. RMS differences between observed DSL and the ensemble of 17 AOGCMs vary between 0.08 and $0.51 \mathrm{~m}$ (Fig. 4). We opt to use only models with a RMS error of less than $0.3 \mathrm{~m}$ (Yin et al. 2010). This threshold eliminates four models from further analysis. We also omit the models GISS AOM and GISS-EH because they include a contribution from land ice which cannot be separated from the steric signal (Katsman et al. 2008). This leaves 11 AOGCMs for the calculation of future regional ocean density and circulation changes for Norway.

\subsubsection{Future ocean mass changes}

Temperature and precipitation fields from the AOGCMs are used to calculate future land ice mass changes, which can be split into the contributions from (1) glaciers and ice caps and (2) from the ice sheets. Ice mass changes are based on scenarios $\mathrm{A} 2, \mathrm{~A} 1 \mathrm{~B}$ and $\mathrm{B} 1$ and results from around 12 of the AOGCMs available from the CMIP3 database (see Slangen et al. (2012) for details).
Slangen et al. (2012) employ a glacier model based on the volume-area scaling approach. Following this method, temperature and precipitation fields from the AOCGMs are used to calculate glacier area changes. Glacier volume is then related to glacier area using a power law (e.g. Bahr et al. 1997). The glacier inventory used is divided into 19 regions (Radić and Hock 2010) and we have separate ice mass projections for each region. Note that as no complete glacier inventory exists, upscaling was performed in 10 of the 19 regions (Radić and Hock 2010).

Future ice mass changes from the ice sheets (Greenland and Antarctica) are the same as in IPCC AR4. That is, projected surface mass balance changes are calculated following Gregory and Huybrechts (2006). (Note that modeled changes in ice sheet flow are also taken into account by modifying the sea level contribution due to surface mass balance changes). In addition, we opt to use the so called scaled-up values for future ice-dynamic changes (see Meehl et al. 2007). Here the present-day global ice sheet imbalance $(0.32 \mathrm{~mm} / \mathrm{year}$ for the period 1993-2003) scales linearly with the projected average atmospheric temperature change. As in Slangen et al. (2012), the scaled-up values for future ice-dynamics are divided assuming a $1 / 3$ contribution from Greenland and 2/3 from Antarctica.

Projected ice mass changes are confined to the areas of southwest Greenland and the Antarctic Peninsula.

\subsubsection{Future non-uniform sea-level changes due to land ice changes}

Predictions of future RSL changes are generated using the sea level model described in Sect. 2.2. The ice model input consists of the projected ice sheet and glacier mass changes
Fig. 4 The root mean square error between the modeled and observed DSL for the period 1992 to 2002. Models with a RMS error larger than the $0.3 \mathrm{~m}$ threshold (dashed line) were excluded from computing future DSL changes for Norway

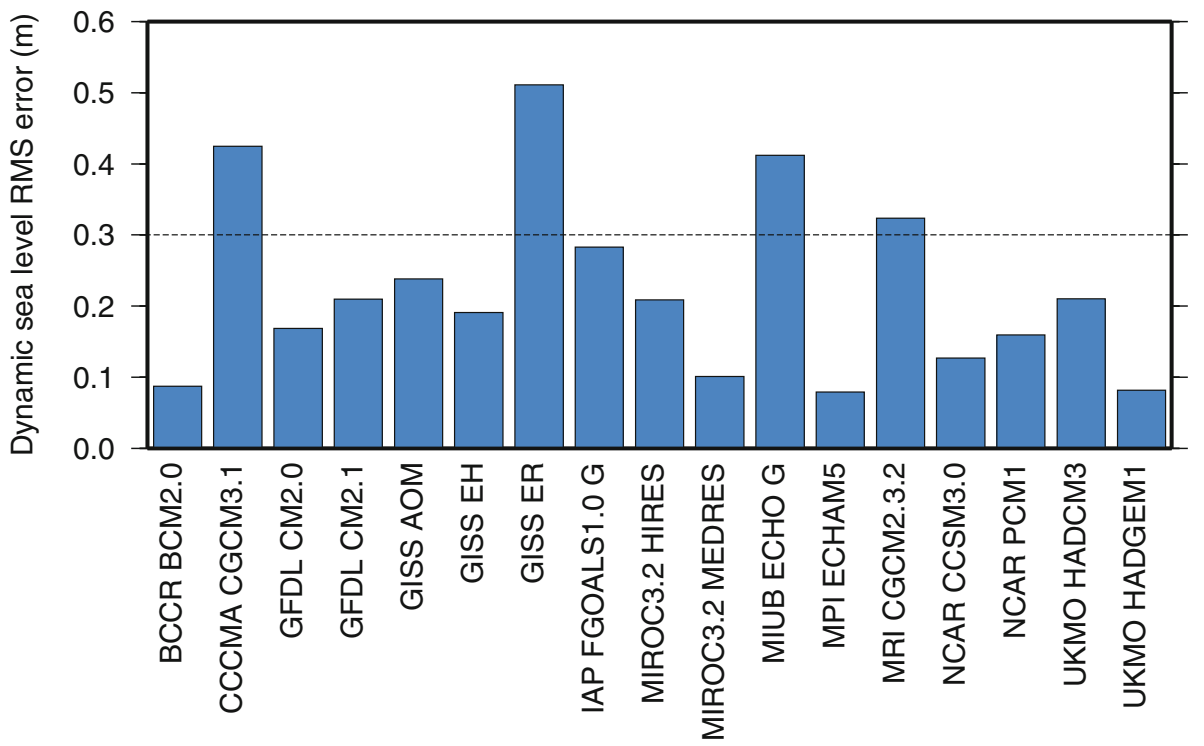


as detailed above. Note that for the Earth response, we assume that deformations over the next century will be purely elastic. Projected ice mass loss, therefore, will lead to a relatively localized elastic rebound of the Earth's surface. As both the elastic Earth response and ocean surface perturbation scales linearly with the surface loading change, non-uniform sea-level changes can be normalized by the ice mass loss (e.g. Mitrovica et al. 2001b):

$$
\begin{aligned}
S_{I}(\theta, \phi)= & V_{A} \times S_{A}^{n}(\theta, \phi)+V_{G} \times S_{G}^{n}(\theta, \phi)+\sum_{m=1}^{19} V_{R}^{m} \\
& \times S_{R}^{n, m}(\theta, \phi)
\end{aligned}
$$

Equation 4 describes how the total projected sea-level change $\left(S_{I}(\theta, \phi)\right)$ is the sum of the normalized sea-level change $\left(S^{n}(\theta, \phi)\right)$ multiplied by the individual projections of ice mass changes for the glacier and ice sheets. Mass changes are given for Antarctica $\left(V_{A}\right)$, Greenland $\left(V_{G}\right)$ and the 19 glacier regions $\left(V_{R}\right)$. Predictions of sea-level change are non-uniform being a function of $(\theta)$ latitude and $(\phi)$ longitude.

\subsection{Projected twenty-first century regional RSL} changes based on IPCC AR4

\subsubsection{Projected global sea-level changes}

We divide our analysis into projected global and regional sea level estimates.

Projected contributions to global mean sea-level change are essentially the same as given by Slangen et al. (2012). We note that the thermal expansion term is slightly different here as we opt to use a different set of AOGCMs. It is important to note that, for both projections of ocean density and ocean mass (land ice) change, we find that the multi-model range overlaps between the scenarios. In other words, there is little difference between projections from A2, A1B and B1 (Meehl et al. 2007). Given this, we present here the multi-model average across all scenarios with a corresponding 1-sigma uncertainty.

As mentioned, global ocean density changes can be approximated as the global mean thermal expansion because global salinity changes are very small. We compute thermosteric sea-level change across scenarios A2, $\mathrm{A} 1 \mathrm{~B}$ and $\mathrm{B} 1$ as $0.22 \pm 0.06 \mathrm{~m}$ (1-sigma) for the period 2090-2099 relative to 1980-1999. Note that the standard deviation only quantifies the variability of the AOGCMs and not the uncertainty on the individual model projections. Table 3 shows the contributions to projected global mean sea-level changes. We do not include the effect of GIA on ocean basin volume changes but this is predicted to be small (Tamisiea 2011). The sum of mean sea-level changes across scenarios A2, A1B and B1 is
$0.47 \pm 0.08 \mathrm{~m}$ (1-sigma). This is useful to know as we can then see how different our regional projections are when compared to the global mean.

\subsubsection{Projected regional ocean density and circulation changes}

We show projected DSL patterns forced using the A1B scenario for the 11 AOGCMs selected in Sect. 3.1.1 (Fig. 5). The models indicate that local sea-level changes owing to ocean density and circulation changes will, generally speaking, be larger than the global mean. Previous modeling studies have focused on identifying the contributing factors to regional differences in AOGCMs (e.g. Landerer et al. 2007; Meehl et al. 2007; Katsman et al. 2008; Yin et al. 2010; Pardaens et al. 2011) and we go on to address this in the Discussion (Sect. 4). Visual inspection of the fields indicates that differences within our study area are no larger than a few centimeters. Thus, given the somewhat larger range between the AOGCMs, local variations along the Norwegian coast are not taken into account. For the period 2090-2099 relative to 1980-1999, we calculate the multi-model average across scenarios A2, $\mathrm{A} 1 \mathrm{~B}$ and $\mathrm{B} 2$ as $0.09 \pm 0.08 \mathrm{~m}$ (1-sigma). This is our estimate for twenty-first century regional DSL changes along the Norwegian coast.

\subsubsection{Projected non-uniform sea-level changes due to land ice changes}

There are relatively small differences between the projected ice mass changes for the different scenarios (see Table 3 and Slangen et al. (2012)). It is not surprising, therefore, that corresponding sea-level changes for Norway are also similar. As with the ocean density and circulation projections, we calculate the multi-model average across scenarios A2, A1B and B2 (Fig. 6). Note that the local uncertainty, which is not shown, varies

Table 3 Contributions to projected twenty-first century (2090-2099 relative to 1980-1999) global mean sea-level change across scenarios $\mathrm{A} 2, \mathrm{~A} 1 \mathrm{~B}$ and $\mathrm{B} 1$

\begin{tabular}{ll}
\hline & Contribution to global mean sea-level change $(\mathrm{m})$ \\
\hline Steric & $0.22 \pm 0.06(47 \%)$ \\
Glaciers* & $0.17 \pm 0.04(36 \%)$ \\
Greenland* & $0.07 \pm 0.02(15 \%)$ \\
Antarctica* & $0.01 \pm 0.02(2 \%)$ \\
Sum & $0.47 \pm 0.08$ \\
\hline
\end{tabular}

Uncertainties are 1-sigma and contributions are also expressed as percentages of the global mean. *based on numbers from Slangen et al. (2012). Note that the uncertainties on the contributions are summed quadratically 


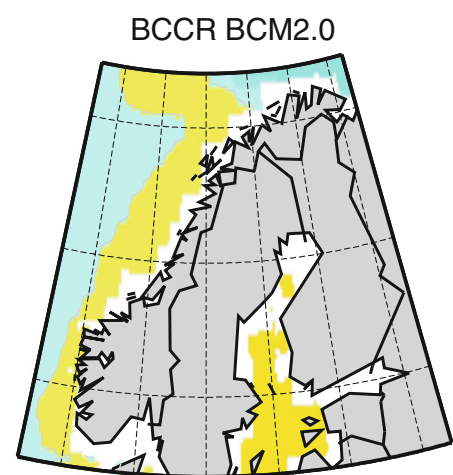

IAP FGOALS1.0 G

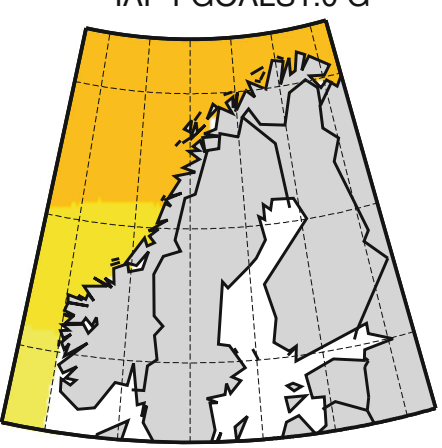

MPI ECHAM5

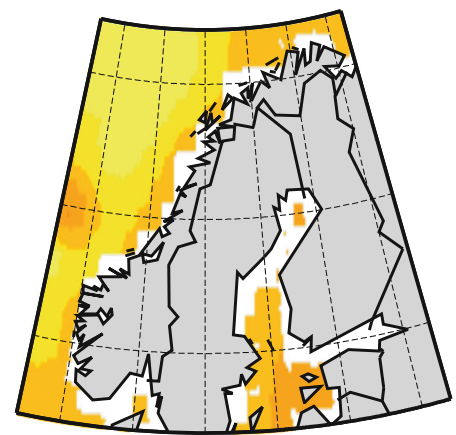

UKMO HADCM3

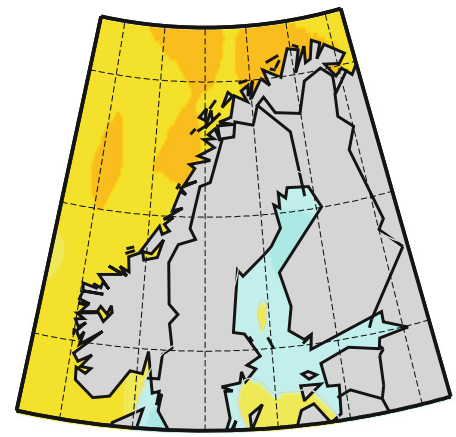

GFDL CM2.0

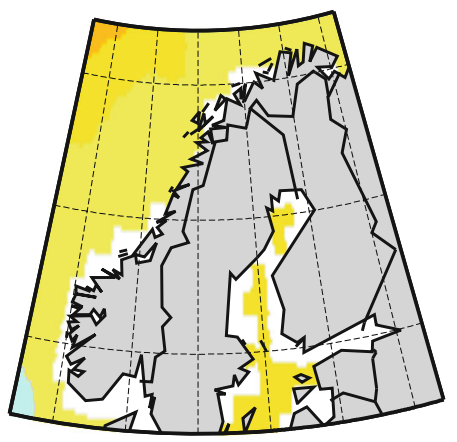

MIROC3.2 HIRES

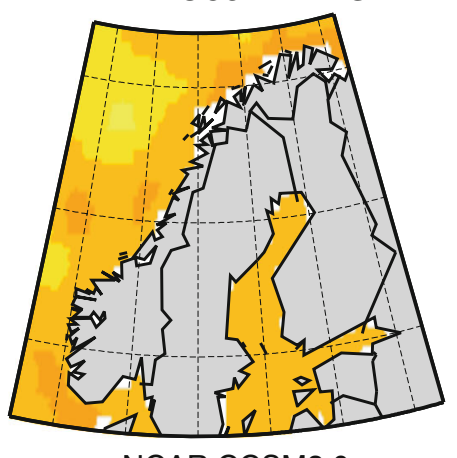

NCAR CCSM3.0

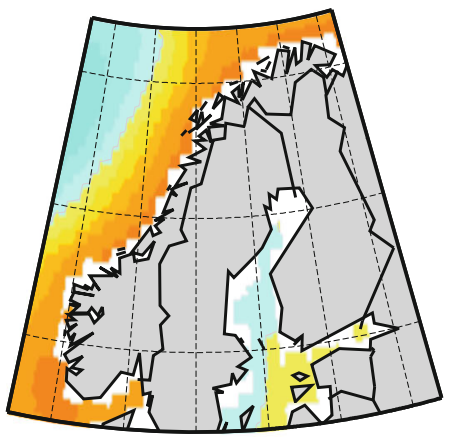

UKMO HADGEM1

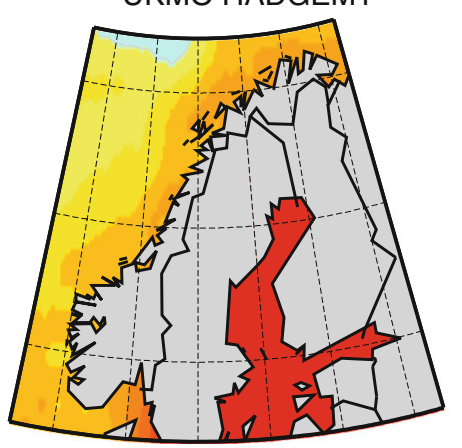

GFDL CM2.1

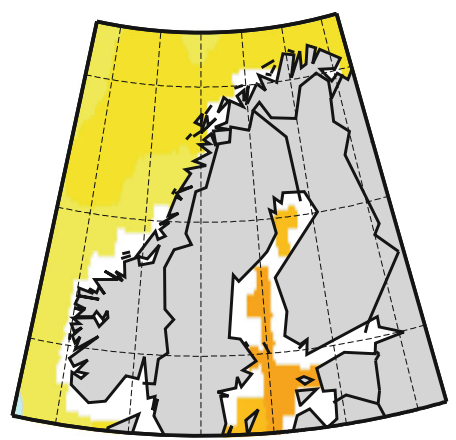

MIROC3.2 MEDRES

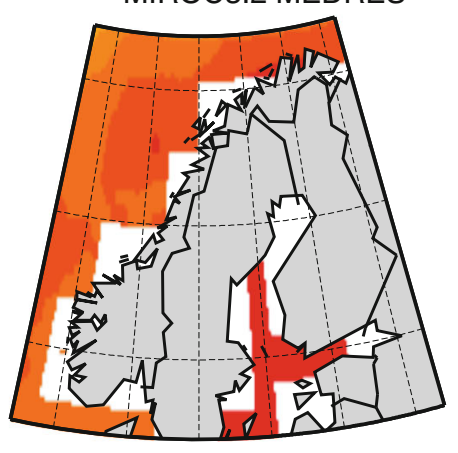

NCAR PCM1
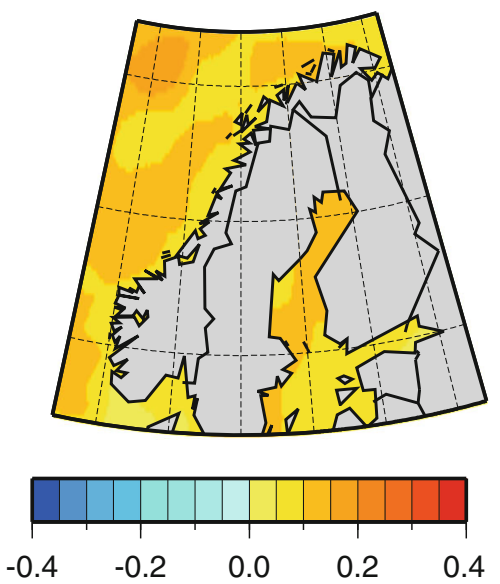

Fig. 5 Projected twenty-first century (2090-2100 relative to 1981-2000) dynamic sea-level changes for the A1B scenario (units are in meters). The 11 AOGCMs shown are those which are able to adequately reproduce the observed pattern of present-day DSL (see Fig. 4)

between \pm 0.035 and $0.04 \mathrm{~m}$ (1-sigma) along the Norwegian coast. The projections in Fig. 6 show significant regional variations; sea-level changes in the south of Norway $(\sim 0.16 \mathrm{~m})$ are approximately twice as large as those in north $(\sim 0.08 \mathrm{~m})$.
We are also able to analyze the sea-level response generated from individual ice masses. This indicates that the north-south gradient in the projections is largely due to changes of glaciers and ice caps. Note that the contribution from the nearby Scandinavian glaciers is found to be less 


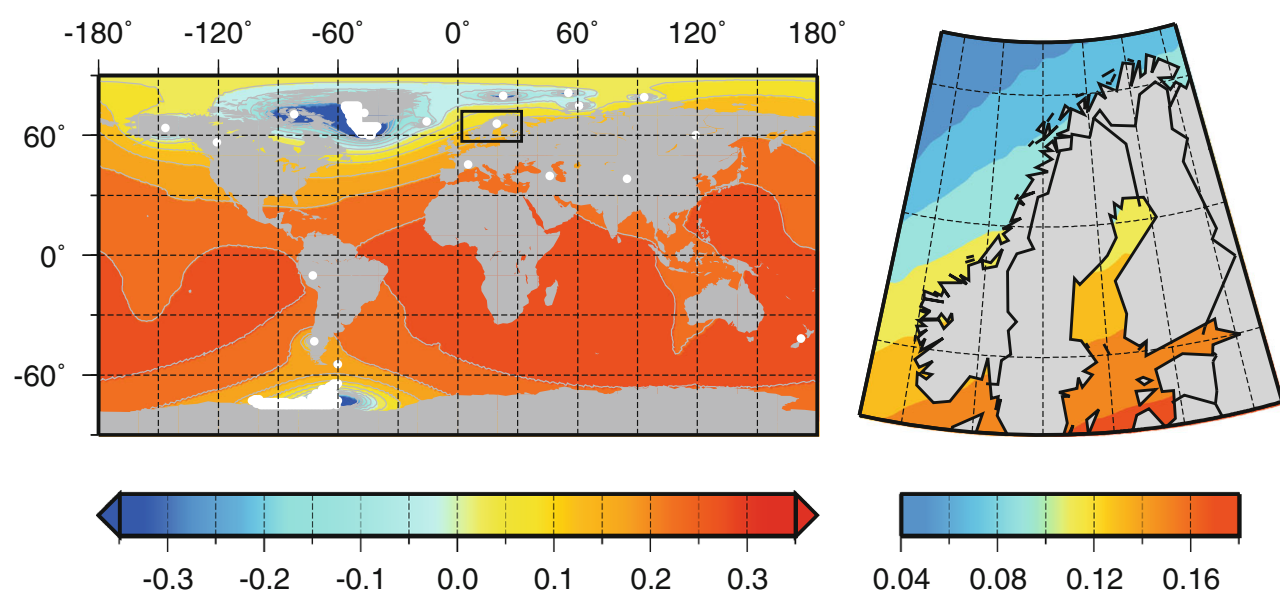

Fig. 6 Projected twenty-first century (2090-2099 relative to 1980-1999) sea-level changes due to variations in land ice (units are in meters). We show the multi-model average across scenarios

than $0.01 \mathrm{~m}$ as their mass changes are so small. When considering the large ice sheets, we find that ice mass changes in southwest Greenland will lead to an almost negligible sea level response for Norway. On the other hand, changes on the Antarctic Peninsula generate a sea level signal which is between 10 and $20 \%$ larger than the global mean. We do not show these individual patterns here but refer the reader to the existing literature (e.g. Gomez et al. 2010; Mitrovica et al. 2011; Tamisiea and Mitrovica 2011) which show sea level projections generated from changes in Greenland and Antarctica, and details of how they deviate from the global mean. These studies also show that the sea level response is highly sensitive to the assumed pattern of ice mass change and the underlying physics of the sea level model applied (see also the Discussion in Sect. 4).

\subsubsection{Projected twenty-first century regional RSL changes based on IPCC AR4}

Here we give regional RSL projections for the end of the twenty-first century using the multi-model average across scenarios A2, A1B and B2 (Fig. 7). As shown above, we estimate global thermal expansion as $0.22 \pm 0.06 \mathrm{~m}$ and regional dynamic sea-level change as $0.09 \pm 0.08 \mathrm{~m}$. Thus, total ocean density and circulation changes are projected to be $0.31 \pm 0.1 \mathrm{~m}$ (1-sigma) for the period 2090-2099 relative to 1980-1999. Non-uniform sea-level changes due to land ice mass changes range between 0.08 and $0.16 \mathrm{~m}$ (with a 1-sigma uncertainty of $\pm 0.04 \mathrm{~m}$ ). Vertical land motion and associated gravitational effects on sea level are taken from the results of our best-fit GIA model. To obtain the cumulative GIA effect for the period
$\mathrm{A} 2$, A1B and B1. Locations of ice mass changes in southwest Greenland, the Antarctic Peninsula and the 19 glaciated regions are colored white

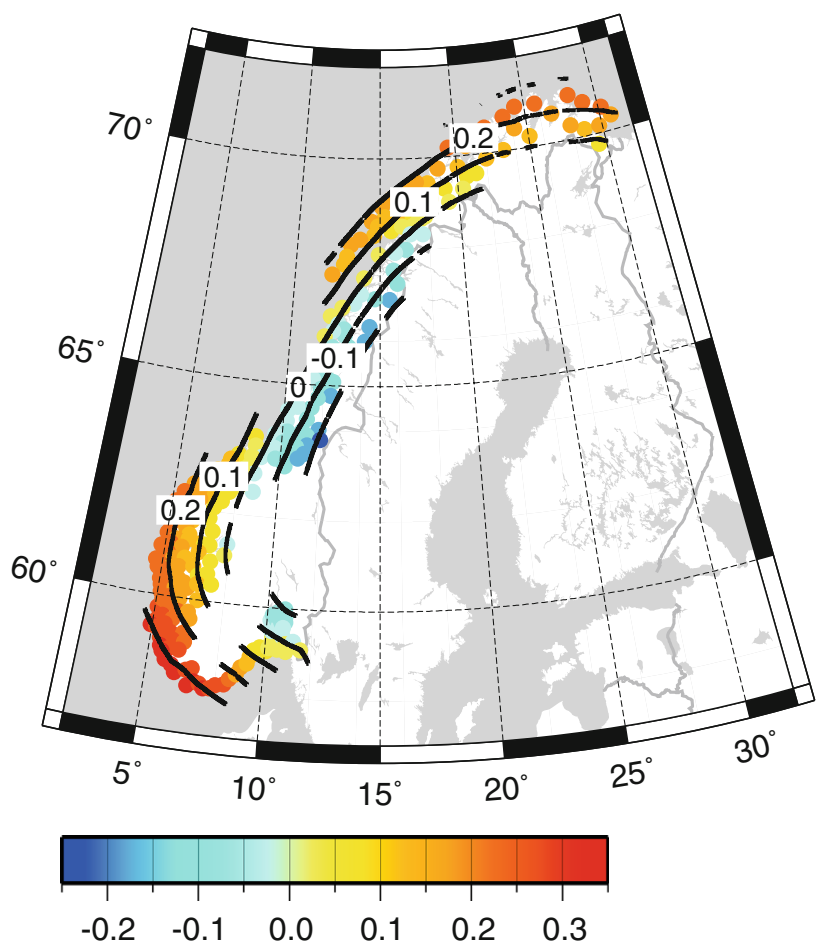

Fig. 7 Projected twenty-first century (2090-2099 relative to 1980-1999) relative sea-level changes using the multi-model average across scenarios A2, A1B and B1 (units are in meters). Our regional estimates take account of (1) ocean density and circulation changes, (2) ice and ocean mass changes and associated gravitational effects on sea-level and (3) vertical land motion and associated gravitational effects arising from past surface loading change. The uncertainty on our projections is $\pm 0.13 \mathrm{~m}$ (1-sigma). Note that the uncertainties on the contributions to RSL change are summed quadratically

2090-2099 relative to 1980-1999 we multiply the rates given in Sect. 2 by 105 years.

Fig. 7 shows that, using the multi-model average across scenarios A2, A1B and B2, projected twenty-first century 
RSL change varies between -0.2 and $0.3 \mathrm{~m}$ (1-sig$\mathrm{ma} \pm 0.13 \mathrm{~m}$ ). Regional RSL changes are between -40 and $60 \%$ of the projected global mean $(0.47 \mathrm{~m})$. The pattern largely reflects vertical land motion due to GIA; this process dominates over ocean density and mass changes in areas where sea-level change is projected to be negative. A summary of projected RSL changes for key locations is given in Table 4. Rather than using results from our GIA model here, we opt to directly use the GNSS observations as we have reliable velocity estimates for these locations (i.e. more than 3 years of data).

\subsection{Projected twenty-first century regional RSL changes for a high-end scenario of climate change}

\subsubsection{Projected high-end global sea-level changes}

Here we explore a scenario of high-end climate change for Norway. As before, we divide our analysis into projected global and regional sea level estimates. To estimate global mean thermal expansion, we make use of the results of Katsman et al. (2011). The authors use two different approaches to extrapolate beyond the temperature range covered by the AOGCMs: (1) they establish a relationship between the change in global atmospheric temperature and global mean thermosteric sea-level change and (2) the change in rates between these two datasets is examined. The latter of these two methods is similar to the semiempirical method of Rahmstorf (2007) except that here it is used in a more restricted way as it is only the thermosteric term that is considered. For an increase in temperature from between 2 and $6{ }^{\circ} \mathrm{C}$, the two different approaches give a global thermosteric sea-level change of 0.12 to $0.49 \mathrm{~m}$ (with a central value of $0.31 \mathrm{~m}$ ).

Projected high-end ocean mass changes can be split into the contributions from (1) glaciers and ice caps, and (2) the large ice sheets. For glaciers and ice caps we take the estimates from Meier et al. (2007). They examine two scenarios, firstly assuming that the observed present-day imbalance will remain constant over the twenty-first century, which results in a $0.1 \pm 0.03 \mathrm{~m}$ contribution for 2006 to 2100. Secondly, assuming present accelerations continue, this leads to a total sea-level change of $0.24 \pm 0.13 \mathrm{~m}$ for the same period. Extending the time interval back to 1990 would only make a small difference $(\sim 0.01 \mathrm{~m})$ to our results. We note that the IPCC AR4 assess the contribution of glaciers and ice caps as $0.77 \pm 0.22 \mathrm{~mm} /$ year for 1993 to 2003 (Lemke et al. 2007). Accounting for the uncertainty on the two scenarios presented by Meier et al. (2007) we find the range for glacier changes is between 0.08 and $0.37 \mathrm{~m}$ (central value $0.23 \mathrm{~m}$ ).

For the ice sheets, we take the severe scenario from Katsman et al. (2011). Here the authors use similar estimates for surface mass balance changes as in IPCC AR4. Ice-dynamic changes are based on expert judgment, which is aided using recent geodetic observations of ice mass changes. This approach allows the authors to roughly estimate possible high-end contributions from the ice sheets but, clearly, it does not tell us how these changes will relate to future climate or temperature change. Katsman et al. (2011) estimate a global mean contribution of 0.13 to $0.22 \mathrm{~m}$ (central value $0.18 \mathrm{~m}$ ) from Greenland for the period 1990 to 2100 . These values are not dissimilar to those obtained in a detailed assessment by Dahl Jensen et al. (2009) in which the authors take ice flux estimates from Pfeffer et al. (2008) to place an upper bound of $\sim 0.2 \mathrm{~m}$ from Greenland by 2100 . For Antarctica, the severe scenario of Katsman et al. (2011) is based on the case of an emerging collapse for some areas of the ice sheets. This gives a global mean contribution of -0.01 to $0.41 \mathrm{~m}$ (central value $0.2 \mathrm{~m}$ ) from Antarctica for the period 1990 to 2100.

Table 5 summarizes the separate contributions to global sea level. Total global changes are found by adding the median values of the separate contributions and uncertainties are summed quadratically (Katsman et al. 2011). Thus, for the period approximately 2090-2099 relative to

Table 4 Projected twenty-first century (2090-2099 relative to 1980-1999) RSL changes as an average of scenarios A2, A1B and B1

\begin{tabular}{|c|c|c|c|c|c|}
\hline Location & $\begin{array}{l}\text { Projected ocean density and } \\
\text { circulation changes } \\
(1 \sigma \pm 0.1 \mathrm{~m})\end{array}$ & $\begin{array}{l}\text { Projected non-uniform sea-level } \\
\text { change from land ice } \\
(1 \sigma \pm 0.04 \mathrm{~m})\end{array}$ & $\begin{array}{l}\text { GIA effects of gravity } \\
\text { changes } \\
(1 \sigma< \pm 0.01 \mathrm{~m})\end{array}$ & GNSS data & $\begin{array}{l}\text { Total RSL } \\
\text { change }\end{array}$ \\
\hline Oslo & 0.31 & 0.13 & 0.05 & $-0.54 \pm 0.06$ & $-0.05 \pm 0.12$ \\
\hline Kristiansand & 0.31 & 0.14 & 0.03 & $-0.18 \pm 0.06$ & $0.3 \pm 0.12$ \\
\hline Stavanger & 0.31 & 0.13 & 0.03 & $-0.15 \pm 0.06$ & $0.32 \pm 0.12$ \\
\hline Bergen & 0.31 & 0.12 & 0.03 & $-0.26 \pm 0.07$ & $0.2 \pm 0.13$ \\
\hline Trondheim & 0.31 & 0.11 & 0.05 & $-0.45 \pm 0.07$ & $0.02 \pm 0.13$ \\
\hline Troms $\varnothing$ & 0.31 & 0.8 & 0.04 & $-0.3 \pm 0.06$ & $0.13 \pm 0.12$ \\
\hline
\end{tabular}

For comparison, global mean sea level is projected to be $0.47 \pm 0.08 \mathrm{~m}$ (1-sigma). To find the total RSL change, uncertainties on the contributions to RSL change are summed quadratically 
Table 5 Contributions to high-end projected twenty-first century (approximately 2090-2099 relative to 1980-1999) global mean sealevel change

\begin{tabular}{lll}
\hline & $\begin{array}{l}\text { Contribution to global mean } \\
\text { sea-level change; central } \\
\text { value and range }(\mathrm{m})\end{array}$ & $\begin{array}{l}\text { Central value as a } \\
\text { percentage of the central } \\
\text { global mean }\end{array}$ \\
\hline Steric & $0.31(0.12$ to 0.49$)$ & $34 \%$ \\
Glaciers & $0.23(0.08$ to 0.37$)$ & $25 \%$ \\
Greenland & $0.18(0.13$ to 0.22$)$ & $20 \%$ \\
Antarctica & $0.20(-0.01$ to 0.41$)$ & $22 \%$ \\
Sum & $0.91(0.59$ to 1.22$)$ & \\
\hline
\end{tabular}

Thermosteric changes are from Katsman et al. (2008; 2011). Glacier changes are based on the work of Meier et al. (2007) and ice sheet contributions taken from Katsman et al. (2011). Total global changes are found by adding the median values of the separate contributions and uncertainties are summed quadratically. Due to rounding errors, the sum given in the final row is not exactly equal to the sum of contributions

1980-1999, high-end global mean changes range from 0.59 to $1.22 \mathrm{~m}$ (central value $0.91 \mathrm{~m}$ ).

\subsubsection{Projected high-end regional ocean density and circulation changes}

As before, dynamic sea-level changes are examined using a regional analysis for the Norwegian coast (the areas $0-14^{\circ} \mathrm{E}, 56-66^{\circ} \mathrm{N}$ and $\left.0-34^{\circ} \mathrm{E}, 66-73^{\circ} \mathrm{N}\right)$. We aim to compare projected global temperature changes to the regional DSL changes (e.g. Katsman et al. 2008, 2011). This requires that we first compute a time-series of projected global atmospheric temperature changes from the CMIP3 database. Secondly, we take the DSL changes computed in Sect. 3.2.2. The projected global temperature and DSL changes are averaged over 5-year periods between 2000 and 2100 (Fig. 8). To estimate the trend of the data we use the method outlined by Katsman et al. (2008). In doing so, we adopt a central value as the trend of the dataset and use the 10 and $90 \%$ quintiles to indicate the variability of the data for increasing temperature change. For the Norwegian coast, the resulting dynamic sea-level change for a global warming of $6{ }^{\circ} \mathrm{C}$ is -0.06 to $0.57 \mathrm{~m}$ with a central value of $0.22 \mathrm{~m}$. We note that this is significantly larger than the range of -0.05 to $0.2 \mathrm{~m}$ reported for the Netherlands (Katsman et al. 2011). These results are added to the estimate of global thermosteric sea-level change (see also Katsman et al. (2008)). For a global atmospheric temperature rise of $6{ }^{\circ} \mathrm{C}$, therefore, total sea-level change due to ocean density and circulation changes is given as 0.19 to $0.93 \mathrm{~m}$ (central value $0.53 \mathrm{~m}$ ) for the Norwegian coast.

\subsubsection{Projected high-end non-uniform sea-level changes due to land ice changes}

Estimates of high-end future ice mass changes are taken from Sect. 3.3.1. As before, the separate ice mass estimates are multiplied by their corresponding normalized sea level pattern to find the non-uniform sea level response (see Eq. 4). For glaciers and ice caps, where we use values based on the work of Meier et al. (2007), we assume the same normalized pattern as calculated using the multi-model average of scenarios A2, A1B and B2 (Sect. 3.2.3). Sealevel changes due to melting of glaciers and ice caps are calculated as between 0.04 and $0.18 \mathrm{~m}$ along the Norwegian coast (see also Table 6). Taking the ice sheet estimates from Katsman et al. (2011), corresponding non-uniform sea-level changes in Norway are between -0.01 and $0.02 \mathrm{~m}$ for Greenland and between -0.01 and $0.5 \mathrm{~m}$ for the Antarctic ice sheets. This shows that the Norwegian coastline is relatively insensitive to high-end ice mass changes in Greenland. On the other hand, sea-level changes owing to ice mass loss in Antarctica are above the global mean. Note that our approach here is not entirely consistent as Katsman et al. (2011) propose that future ice mass loss occurs in several different regions rather than in southwest Greenland and on the Antarctic Peninsula as we assume here.

\subsubsection{Projected twenty-first century regional RSL changes for a high-end scenario of climate change}

Here we give regional RSL projections for the end of the twenty-first century for our high-end scenario of climate change. We show the central estimate of projected RSL change, which we find varies between 0.25 and $0.85 \mathrm{~m}$ along the Norwegian coast (Fig. 9). The uncertainties on the sea-level projections show only small spatial variations, so we assign a $\mathrm{min} / \mathrm{max}$ range of $\pm 0.45 \mathrm{~m}$ to our central estimates (see also Table 6). We note that our projected regional RSL changes are between 25 and $95 \%$ of the projected central estimate of the global mean $(0.91 \mathrm{~m})$. Clearly, as RSL changes are positive, this shows ocean surface increases dominate over the land uplift signal across all of Norway. The pattern of RSL change, however, still largely reflects land motion due to GIA.

Table 6 summarizes the individual contributions to projected high-end RSL for key locations in Norway. As before, we opt to directly use the GNSS observations as we have reliable velocity estimates for these locations (i.e. more than 3 years of data). We note that there is large uncertainty associated with both (1) local density and circulation changes and (2) the contribution of the Antarctic ice sheets. Uncertainty with local density and circulation changes reflects the large variation between the AOGCMs 
Fig. 8 Projected regional dynamic sea-level change (the areas $0-14^{\circ} \mathrm{E}, 56-66^{\circ} \mathrm{N}$ and $0-34^{\circ} \mathrm{E}, 66-73^{\circ} \mathrm{N}$ ) versus global atmospheric temperature change. Each dot represents a result from one AOGCM using a 5-year average from the period 2000 to 2100 (relative to 1981-2000). Scenarios A2, A1B and $\mathrm{B} 1$ are marked red, blue and grey respectively. The solid and dashed lines represent trends of the central and lower/upper

boundaries of the data

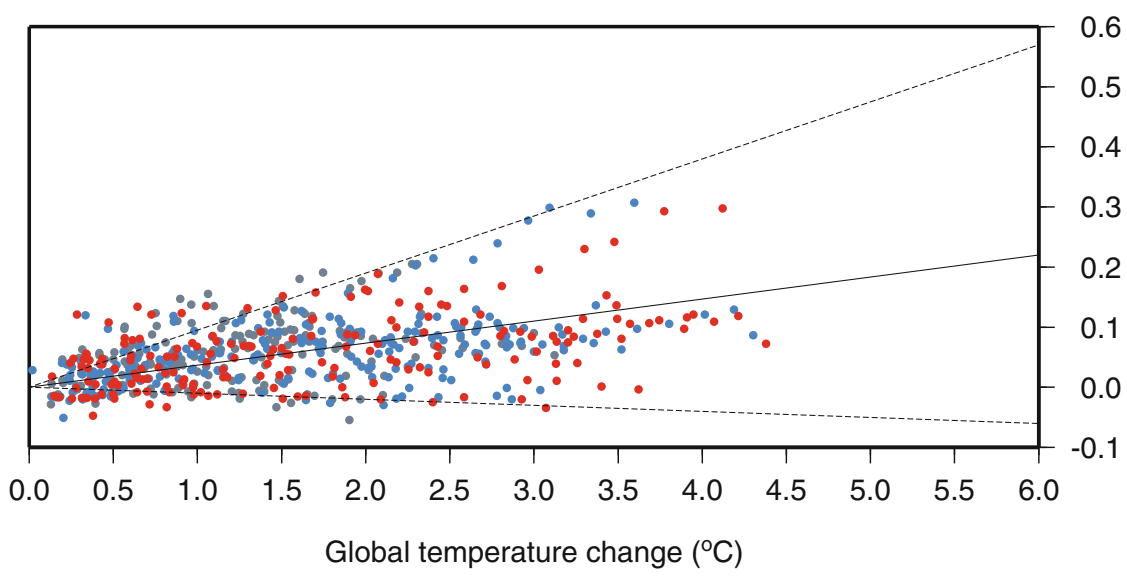

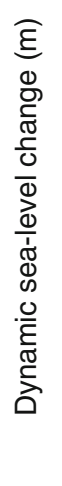

Table 6 Projected high-end twenty-first century (approximately 2090-2099 relative to 1980-1999) sea-level changes at key locations in Norway

\begin{tabular}{|c|c|c|c|c|c|c|c|c|}
\hline Location & $\begin{array}{l}\text { Global } \\
\text { thermal } \\
\text { expansion } \\
\text { (m) }\end{array}$ & $\begin{array}{l}\text { Local ocean } \\
\text { density } \\
\text { changes (m) }\end{array}$ & $\begin{array}{l}\text { Non-uniform } \\
\text { glaciers }(m)\end{array}$ & $\begin{array}{l}\text { Non-uniform } \\
\text { Greenland } \\
\text { (m) }\end{array}$ & $\begin{array}{l}\text { Non-uniform } \\
\text { Antarctica } \\
\text { (m) }\end{array}$ & $\begin{array}{l}\text { GIA gravity } \\
\text { effects } \\
(1 \sigma< \pm 0.01 \mathrm{~m})\end{array}$ & GNSS data & $\begin{array}{l}\text { Total RSL } \\
\text { change } \\
\text { (m) }\end{array}$ \\
\hline Oslo & 0.12 to 0.49 & -0.06 to 0.57 & 0.06 to 0.26 & 0 to 0.01 & -0.01 to 0.49 & 0.05 & $-0.54 \pm 0.06$ & $0.44(-0.01$ to 0.88$)$ \\
\hline Kristiansand & 0.12 to 0.49 & -0.06 to 0.57 & 0.06 to 0.28 & 0 to 0.01 & -0.01 to 0.5 & 0.03 & $-0.18 \pm 0.06$ & 0.83 (0.37 to 1.29$)$ \\
\hline Stavanger & 0.12 to 0.49 & -0.06 to 0.57 & 0.06 to 0.27 & 0 & -0.01 to 0.5 & 0.03 & $-0.15 \pm 0.06$ & $0.85(0.39$ to 1.31$)$ \\
\hline Bergen & 0.12 to 0.49 & -0.06 to 0.57 & 0.06 to 0.26 & 0 & -0.01 to 0.49 & 0.03 & $-0.26 \pm 0.07$ & $0.73(0.27$ to 1.19$)$ \\
\hline Trondheim & 0.12 to 0.49 & -0.06 to 0.57 & 0.05 to 0.23 & 0 & -0.01 to 0.48 & 0.05 & $-0.45 \pm 0.07$ & 0.54 (0.08 to 0.99$)$ \\
\hline Troms $\varnothing$ & 0.12 to 0.49 & -0.06 to 0.57 & 0.03 to 0.15 & 0 & -0.01 to 0.46 & 0.04 & $-0.3 \pm 0.06$ & $0.62(0.17$ to 1.06$)$ \\
\hline
\end{tabular}

The projected ocean density and circulation changes are calculated using the methods of Katsman et al. (2008; 2011). The land ice signal includes an estimation of glacier changes based on the work of Meier et al. (2007) and ice sheet contributions from Katsman et al. (2011). Total RSL changes are found by adding the median values of the separate contributions and uncertainties are summed quadratically. For comparison, global mean sea level is projected to be between 0.59 and $1.22 \mathrm{~m}$ (central value $0.91 \mathrm{~m}$ )

with increasing temperature (see Fig. 8). Whereas, the uncertainty associated with the Antarctic is largely due to the lack of understanding how the marine-based portions of the ice sheets will react in a changing climate. We note that there are some small inconsistencies between the time periods we consider for our high-end contributions but believe this will not greatly influence our final results.

\section{Discussion}

In the following we show observed rates of RSL change from some of the Norwegian tide gauge records (see also Henry et al. 2012; Richter et al. 2012). This helps to put our projections into perspective. In Sect. 4.2 we go on to discuss two main issues: (1) how to reduce the uncertainty of our projections and (2) processes that drive sea-level changes but are not included in this study.

\subsection{Observed present-day RSL change}

In Fig. 10 we show our sea-level projections alongside tide gauge observations from Oslo. The Oslo tide gauge record contains significant gaps during its early period of operation, so we opt to only plot data post 1914 . To obtain an estimate of present-day RSL change for Oslo we conduct a least squares adjustment to determine the trend in the data over the past 30 years. The rate of RSL change over the period 1980 to 2010 is calculated to be $-1.7 \pm 0.7 \mathrm{~mm} /$ year (1-sigma). We correct the tide gauge observations for vertical land motion using the GNSS data and the modeled gravitational effects associated with GIA (Sect. 2). Expressed as contributions to RSL change, these are $5.1 \pm 0.6 \mathrm{~mm} /$ year and $0.5 \pm 0.1 \mathrm{~mm} /$ year respectively. Ocean surface changes are thus calculated to be $2.9 \pm 0.9 \mathrm{~mm} /$ year (1-sigma) over 1980 to 2010 . Table 7 summarizes present-day observed RSL changes and esti- 


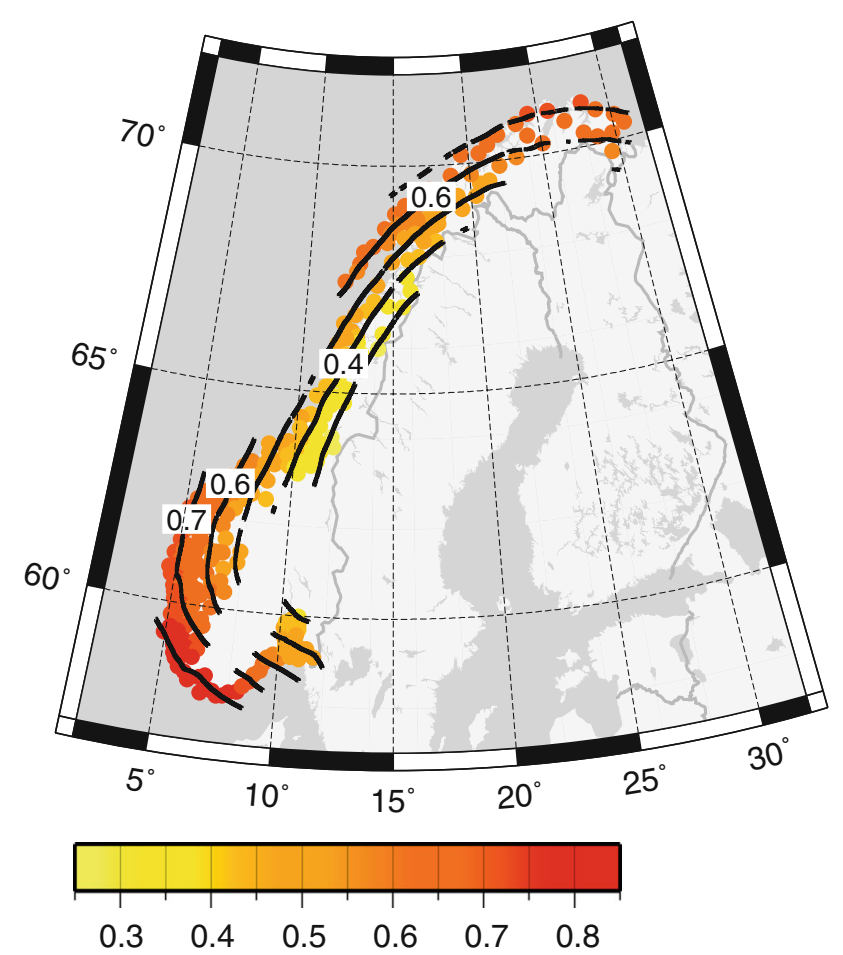

Fig. 9 The median values of our high-end twenty-first century (approximately 2090-2099 relative to 1980-1999) projected relative sea-level changes (units are in meters). Our regional estimates take account of (1) ocean density and circulation changes, (2) ice and ocean mass changes and associated gravitational effects on sea-level, and (3) vertical land motion and associated gravitational effects arising from past surface loading change. The uncertainty on our projections is $\pm 0.45 \mathrm{~m}(\mathrm{~min} / \mathrm{max})$. Note that the uncertainties on the contributions to RSL change are summed quadratically

mated rates of ocean surface rise for key locations in Norway. We note that, generally speaking, rates of ocean surface rise along the Norwegian coast are not dissimilar from the global rate from satellite altimetry (Cazenave and Llovel 2010). Also included in Table 7 are estimates of twenty-first century RSL change assuming that the observed present-day rates continue unchanged. This is rather speculative but provides a yardstick to which our projections can be compared.

\subsection{Reducing the uncertainty of sea-level projections and missing contributions}

The largest uncertainty in future estimates of global sealevel change is the potential contributions from the large ice sheets (e.g. Alley et al. 2005). It is well recognized that there are limitations with the ice models applied in IPCC AR4 (Meehl et al. 2007). For example, processes such as ice stream dynamics, basal sliding and ice-ocean interactions are either poorly represented or absent from the model setup. This gives us reason to believe that these model projections might be biased low. In an attempt to account for this problem, the IPCC AR4 includes an estimate of the present-day ice sheet imbalance due to recent ice flow acceleration, the so called scaled-up contribution, which we also include in our sea-level projections in Sect. 3.2. This is a relatively conservative estimate of how processes affecting ice flow may contribute to sea-level change over the twenty-first century. As mentioned, one reason we opt to also include a high-end projection is because of these issues reported in IPCC AR4. The reader should also keep in mind, however, that the high-end ice loss numbers we adopt from Katsman et al. (2011) are based on expert judgment and the extrapolation of recent geodetic observations (rather than being based on an understanding of how the ice sheets would react in a changing climate).

As well as uncertainties concerning the potential ice sheet contributions, recent works have shown how regional sea-level projections are also sensitive to the pattern of ice mass change (e.g. Gomez et al. 2010; Mitrovica et al. 2011; Tamisiea and Mitrovica 2011). The results of these studies suggest that, as Norway sits in the near field of Greenland, sea-level changes along the Norwegian coast will be highly sensitive to the pattern of ice sheet change. In a simple sensitivity test we generate sea-level projections where the melt is geographically confined to different quadrants on Greenland (in our original analysis we consider only uniform changes in the southwest). Maximum differences between the normalized fingerprints from these 4 scenarios of ice melt are up to $100 \%$ (Fig. 11). This is because ice mass losses on the east of Greenland result in a more negative sea-level change than those in the west. For the case of Antarctica, here Norway sits in the far field, one might expect that sea-level changes will be relatively insensitive to the pattern of ice melt. Recent work, however, shows how projections are sensitive due to the rotational feedback signal (Mitrovica et al. 2011). Future work should focus on including more realistic geometries of ice mass change for both of the large ice sheets.

So far we have considered the uncertainty associated with future ocean mass (land ice) changes. Here we briefly address the uncertainties with projected patterns of ocean density and circulation changes which, generally speaking, show poor agreement (e.g. Gregory et al. 2001; Meehl et al. 2007). Results from AOGCMs indicate an above average sea-level rise for Norway over the twenty-first century but with relatively large uncertainties attached to the projections (Sect. 3.2.2). As mentioned, past modeling studies have focused on identifying the contributing factors to regional differences in projected ocean density and circulation changes (e.g. Landerer et al. 2007; Meehl et al. 2007; Katsman et al. 2008; Yin et al. 2010; Pardaens et al. 2011). These generally show that in the nearby North Atlantic positive thermosteric changes are partially compensated by 


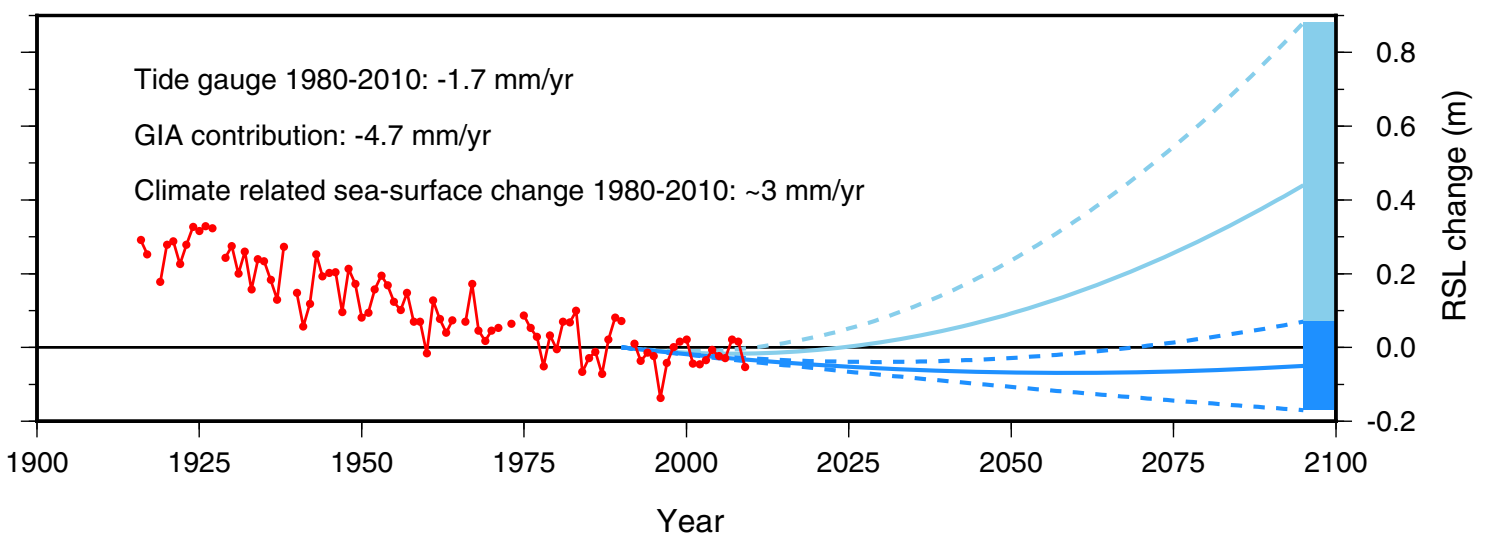

Fig. 10 Projected twenty-first century RSL changes for Oslo shown alongside the Oslo tide gauge record for the period 1914 to 2010. (Note that the tide gauge data are plotted relative to the average of the observations from 1980 to 1999). Dark blue marks our projections largely based on results from IPCC AR4 and using the emission scenarios A2, A1B and B1 (see Sect. 3.2 and Table 4). Here the solid line is the multi-model average and dashed lines the 1-sigma uncertainty. Light blue marks our high-end projection based on the work of Katsman et al. (2011) (see Sect. 3.3 and Table 6). Here the solid line is the central estimate and dashed line the maximum on the range. We fit a 2 nd order polynomial to our high-end projections as a visual guide

Table 7 Analysis of tide gauge observations covering the period 1980 to 2010

\begin{tabular}{llllll}
\hline Location & $\begin{array}{l}\text { RSL rate } 1980 \text { to } \\
\text { 2010 from tide } \\
\text { gauge data }(\mathrm{mm} / \\
\text { year) }\end{array}$ & $\begin{array}{l}\text { Estimated rate of } \\
\text { ocean surface rise } \\
1980 \text { to } 2010(\mathrm{~mm} / \\
\text { year })\end{array}$ & $\begin{array}{l}\text { Total RSL change assuming observed } \\
\text { present-day rates remain unchanged } \\
\text { for 2090-2099 relative to 1980-1999 } \\
(\mathrm{m})\end{array}$ & $\begin{array}{l}\text { Projected twenty- } \\
\text { first century RSL } \\
\text { changes based on } \\
\text { IPCC AR4 }\end{array}$ & $\begin{array}{l}\text { Projected twenty-first } \\
\text { century RSL changes } \\
\text { for a high-end } \\
\text { scenario }\end{array}$ \\
\hline Oslo & $-1.7 \pm 0.7$ & $2.9 \pm 0.9$ & $-0.18 \pm 0.09$ & $-0.05 \pm 0.12$ & $0.44(-0.01$ to 0.88$)$ \\
Kristiansand & $0.2 \pm 0.5$ & $1.6 \pm 0.8$ & $0.02 \pm 0.08$ & $0.3 \pm 0.12$ & $0.83(0.37$ to 1.29$)$ \\
Stavanger & $1.8 \pm 0.4$ & $3 \pm 0.7$ & $0.19 \pm 0.07$ & $0.32 \pm 0.12$ & $0.85(0.39$ to 1.31$)$ \\
Bergen & $1.1 \pm 0.4$ & $3.3 \pm 0.8$ & $0.12 \pm 0.08$ & $0.2 \pm 0.13$ & $0.73(0.27$ to 1.19$)$ \\
Trondheim & Omitted & & & $0.02 \pm 0.13$ & $0.54(0.08$ to 0.99$)$ \\
Troms $\varnothing$ & $0.8 \pm 0.5$ & $3.3 \pm 0.8$ & $0.08 \pm 0.08$ & $0.13 \pm 0.12$ & $0.62(0.17$ to 1.06$)$ \\
\hline
\end{tabular}

In column 3 we give estimated rates of ocean surface rise which have been corrected for (1) vertical land motion using the GNSS data and (2) gravitational effects on sea level using our best-fit GIA model. Total RSL changes for the period 2090-2099 relative to 1980-1999 changes are found by multiplying the observed present-day rates in column 2 by 105 years. Column 5 is taken from Table 4 . Column 6 is from Table 6 . We omit the tide gauge from Trondheim because it was moved in 1991

a negative halosteric signal. Whereas, in the Arctic Ocean, the halosteric term is positive and dominates due to ocean freshening. Related to these steric changes is a mass redistribution term which could be important for the shallow shelf seas around Norway (see Landerer et al. (2007) for details). We also note that other ocean dynamic signals have been linked to regional ocean surface changes. For example, in their study of the Dutch coast, Katsman et al. (2008) suggest a strong link between ocean surface rise and a weakening of the Atlantic meridional overturning circulation. This may explain why our high-end estimate of sealevel changes associated with ocean density and circulation changes has such a large uncertainty term (Sect. 3.3.2).

Finally, we list some of the processes that could affect future sea-level changes for Norway but are not taken account of in this study. We first consider the land motion signal. As in previous works, the GNSS observations (Kierulf et al. 2013) and modeling work performed here suggest that GIA dominates the regional pattern of Earth response in Norway. Other effects such as tectonics and subsidence are not examined and could be important for determining local RSL changes. We also note that the influence of GIA on ocean basin volume changes is not included here, but this effect is relatively small (Tamisiea 2011). For ocean mass changes, we only consider changes associated with glaciers and the large ice sheets. Other sources such as changes in dam impoundment (Chao et al. 2008) and groundwater pumping (Wada et al. 2010) are not taken into account. Recent work suggests that their cumulative contributions to twenty-first century global sea-level change will not be 


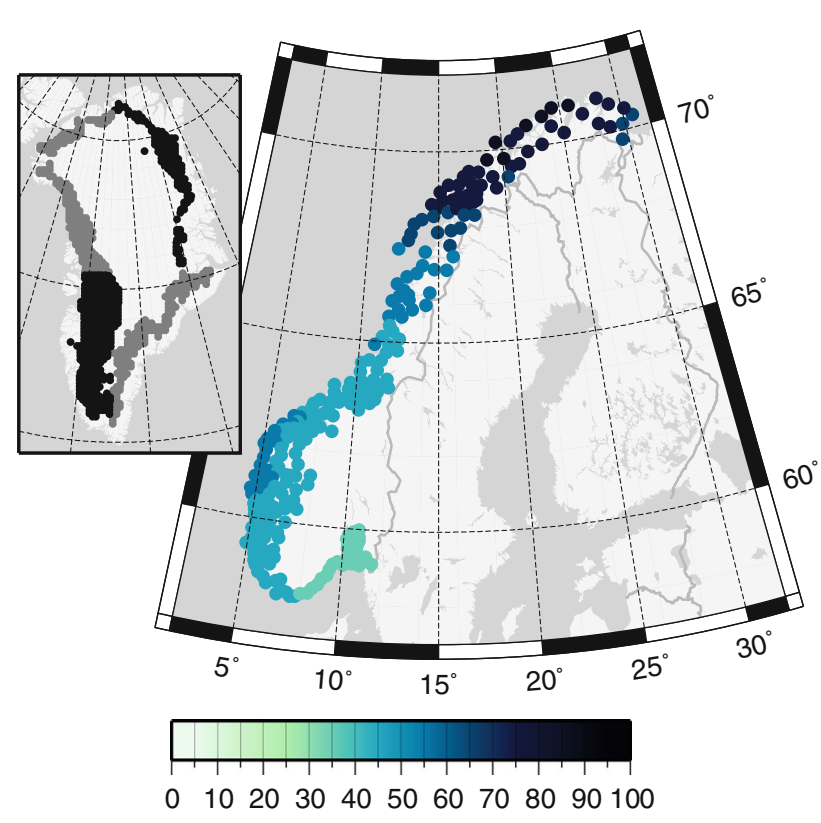

Fig. 11 The sensitivity of sea-level changes in Norway to the pattern of ice mass change on Greenland. We generate sea-level projections where ice mass changes are geographically confined to different quadrants on Greenland (left). Note that the overall pattern of melt is adapted from passive microwave observations (Abdalati 2007). Maximum differences between the normalized fingerprints from these 4 scenarios of ice melt are presented as percentages (right)

larger than $0.1 \mathrm{~m}$ (Wada et al. 2012). Such mass changes could also be important for determining local RSL changes. Concerning ocean density and circulation changes, we note that the AOGCMs included in our study do not include the effect of ocean freshening and associated ocean surface changes arising from land ice melt. This effect could potentially be important along the Norwegian coast but modeling work is still in its infancy (Stammer 2008; Stammer et al. 2011; Brunnabend et al. 2012).

\section{Conclusions}

We have conducted the first detailed analysis of twentyfirst century regional sea-level changes for Norway by accounting for spatial variations in (1) ocean density and circulation (2) ice and ocean mass changes and associated gravitational effects on sea level and (3) vertical land motion arising from past surface loading change and associated gravitational effects on sea level. Central to our study is an assessment of vertical land motion using new observations from a permanent GNSS network (Kierulf et al. 2013). As show in previous studies, the observed pattern of Earth response in Norway is dominated by the process of GIA. We use the new GNSS data to constrain a model of GIA. Predictions generated from our best-fit GIA model indicate that uplift rates along the Norwegian coast are between 1 and $5 \mathrm{~mm} /$ year (or between -0.1 and $0.5 \mathrm{~m}$ as a contribution to twenty-first century RSL change). For areas where we currently lack reliable GNSS data, for example in the middle of Norway, the GIA model provides a useful tool for estimating vertical land motion.

Our projections of twenty-first century sea-level change for Norway show a pattern of complex interplay between vertical land motion and non-uniform ocean surface changes. We present two sets of projections. Firstly, we first calculate future sea-level changes based on findings largely from the IPCC AR4 and using the emission scenarios A2, A1B and B1. These indicate that for the period 2090-2099 relative to 1980-1999 RSL changes in Norway will vary between -0.2 to $0.3 \mathrm{~m}$ (1-sigma $\pm 0.13 \mathrm{~m}$ ). Projected regional RSL changes are between -40 and $60 \%$ of the projected global mean $(0.47 \mathrm{~m})$. Owing to a lack of understanding of the processes that drive sea-level changes and model limitations, we have reason to believe that these projections might be biased low (Meehl et al. 2007). Secondly, we explore a high-end scenario in which (1) a global atmospheric temperature rise of up to $6{ }^{\circ} \mathrm{C}$ and (2) an emerging collapse for some areas of the Antarctic ice sheets are assumed (Katsman et al. 2011). Using this approach, we find twenty-first century RSL changes in Norway will vary between 0.25 and $0.85 \mathrm{~m}(\mathrm{~min} /$ $\max \pm 0.45 \mathrm{~m})$. Projected regional RSL changes are between 25 and $95 \%$ of the projected central estimate of the global mean $(0.91 \mathrm{~m})$. Thus, both sets of projections suggest that twenty-first century sea-level changes in Norway will be below the global mean.

Our work here underlines the importance of working towards regional projections of sea-level change. By isolating the individual processes that drive sea-level changes, we are able to better understand their relative contributions. This will help guide future research as we seek to better constrain our projections. The analysis performed here should be updated as new methods and results become available. For example, by using new model results from the CMIP5 database. Finally, we note that while this study has focused on twentyfirst century sea-level changes, global sea level will continue to rise well beyond 2100 (e.g. Goelzer et al. 2012).

Acknowledgments First and foremost we thank A. Slangen for providing data on the ice mass changes. We acknowledge the modeling groups, the Program for Climate Model Diagnosis and Intercomparison (PCMDI) and the WCRP's Working Group on Coupled Modelling (WGCM) for their roles in making available the WCRP CMIP3 multi-model dataset. Support of this dataset is provided by the Office of Science, U.S. Department of Energy. All figures were produced using the GMT software.

Open Access This article is distributed under the terms of the Creative Commons Attribution License which permits any use, distribution, and reproduction in any medium, provided the original author(s) and the source are credited. 


\section{References}

Abdalati W (2007) Greenland ice sheet melt characteristics derived from passive microwave data, 2004. Boulder, Colorado USA: National Snow and Ice Data Center. Digital media

Alley RB, Clark PU, Huybrechts P, Joughin I (2005) Ice-sheet and sea-level changes. Science 310:456-460

Altamimi Z, Collilieux X, Métivier L (2011) ITRF2008: an improved solution of the international terrestrial reference frame. J Geod 85(8):457-473. doi:10.1007/s00190-011-0444-4

Bahr DB, Meier MF, Peckham SD (1997) The physical basis of glacier volume-area scaling. J Geophys Res 102(B9): 20,355-20,362

Brunnabend S-E, Schröter J, Timmerman R, Rietbroek R, Kusche J (2012) Modeled steric and mass-driven sea level change caused by Greenland Ice Sheet melting. J Geodyn 59-60:219-225. doi:10.1016/j.jog.2011.06.001

Cazenave A, Llovel W (2010) Contemporary sea level rise. Ann Rev Mar Sci 2:145-173

Cazenave A, Dominh K, Guinehut S, Berthier E, Llovel W, Ramilien G, Ablain M, Larnicol G (2009) Sea level budget over 2003-2008. A reevaluation from GRACE space gravimetry, satellite altimetry and ARGO. Glob Planet Change 65:83-88. doi:10.1016/j.gloplacha.2008.10.004

Chao BF, Wu YH, Li YS (2008) Impact of artificial reservoir water impoundment on global sea level. Science 320(212). doi:10. $1126 /$ science. 1154580

Church JA, Gregory JM, White NJ, Platten SM, Mitrovica JX (2011) Understanding and projecting sea level change. Oceanogr 24(2):130-143. doi:10.5670/oceanog.2011.33

Collins WD, Bitz CM, Blackmon ML, Bonan GB, Bretherton CS, Carton JA, Chang P, Doney SC, Hack JJ, Henderson TB et al (2006) The community climate system model version 3 (CCSM3). J Clim 19(11):2122-2143

Dahl Jensen D, Bamber J, Bøggild CE, Buch E, Christensen JH, Dethloff K., Fahnestock M, Marshall S, Rosing M, Steffen K., Thomas R, Truffer M, van den Broeke M, van der Veen CJ (2009) The Greenland ice sheet in a changing climate: snow, water, ice and permafrost in the arctic (SWIPA). Arctic Monitoring and Assessment Programme (AMAP), Oslo, pp. 115

Delworth TL, Broccoli AJ, Rosati A, Stouffer RJ, Balaji V, Beesley JA, Cooke WF, Dixon KW, Dunne J, Dunne KA, Durachta JW, Findell KL, Ginoux P, Gnanadesikan A, Gordon CT, Griffies SM, Gudgel R, Harrison MJ, Held IM, Hemler RS, Horowitz LW, Klein SA, Knutson TR, Kushner PJ, Langenhorst AR, Lee HC, Lin SJ, Lu J, Malyshev SL, Milly PCD, Ramaswamy V, Russell J, Schwarzkopf MD, Shevliakova E, Sirutis JJ, Spelman MJ, Stern WF, Winton M, Wittenberg AT, Wyman B, Zeng F, Zhang R (2006) GFDL's CM2 global coupled climate models. Part I: formulation and simulation characteristics. J Clim 19:643-674

Dziewonski AM, Anderson DL (1981) Preliminary reference Earth model. Phys Earth Planet Inter 25(4):297-356. doi:10.1016/ 0031-9201(81)90046-7

Ekman M (1996) A consistent map of the postglacial uplift of Fennoscandia. Terra Nova 8:158-165. doi:10.1111/j.1365-3121. 1996.tb00739.x

Farrell WE, Clark JA (1976) On postglacial sea level. Geophys J R Astron Soc 46:647-667

Fjeldskaar W (1994) Viscosity and thickness of the asthenosphere detected from the Fennoscandian uplift. Earth Planet Sci Lett 126:399-410. doi:10.1016/0012-821X(94)90120-1

Flato GM (2005) The third generation coupled global climate model (CGCM3). http://www.cccma.ec.gc.ca/models/cgcm3.shtml

Furevik T, Bentsen M, Drange H, Kvamsto N, Sorteberg A (2003) Description and evaluation of the Bergen climate model: ARPEGE coupled with MICOM. Clim Dyn 21:27-51
Goelzer H, Huybrechts P, Raper SCB, Loutre M.-F, Goosse H, Fichefet T (2012) Millenial total sea-level commitments projected with the Earth system model of intermediate complexity LOVECLIM. Environ Res Lett 7(045401). doi:10.1088/17489326/7/4/045401

Gomez N, Mitrovica JX, Tamisiea ME, Clark PU (2010) A new projection of sea level change in response to collapse of marine sectors of the Antarctic Ice Sheet. Geophys J Int 180:623-634. doi:10.1111/j.1365-246X.2009.04419.x

Gordon C, Cooper C, Senior CA, Banks HT, Gregory JM, Johns TC, Mitchell JFB, Wood RA (2000) The simulation of SST, sea ice extents and ocean heat transports in a version of the Hadley Centre coupled model without flux adjustments. Clim Dyn 16:147-168

Gregory JM, Huybrechts P (2006) Ice-sheet contributions to future sea-level change. Phil Trans R Soc A 364:1709-1731. doi:10. 1098/rsta.2006.1796

Gregory JM, Church JA, Boer GJ, Dixon KW, Flato GM, Jackett DR, Lowe JA, O'Farrell SP, Roeckner E, Russell GL, Stouffer RJ, Winton M (2001) Comparison of results from several AOGCMs for global and regional sea-level change 1900-2100. Clim Dyn $18: 225-240$

Hasumi H, Emori S (2004) K-1 coupled model (MIROC) description. Center for Climate System Research, University of Tokyo, K-1 Tech. Rep, 1, p. 34

Henry O, Prandi P, Llovel W, Cazenave A, Jevrejeva S, Stammer D, Meyssignac B, Koldunov NV (2012) Tide gauge-based sea level variations since 1950 along the Norwegian and Russian coasts of the Arctic Ocean; Contribution of the steric components. J Geophys Res. doi:10.1029/2011JC007706

Herring TA, King RW, McClusky SC (2010) Introduction to GAMIT/ GLOBK, Release 10.4. http://www-gpsg.mit.edu/ simon/gtgk/ Intro_GG.pdf

Hill EM, Davis JL, Tamisiea ME, Lidberg M (2010) Combination of geodetic observations and models for glacial isostatic adjustment fields in Fennoscandia, J Geophys Res 115(B07403). doi:10. 1029/2009JB006967

Johansson JM, Davis JL, Scherneck H.-G, Milne GA, Vermeer M, Mitrovica JX, Bennett RA, Jonsson B, Elgered G, Elósegui P, Koivula H, Poutanen M, Rönnäng BO, Shapiro II (2002) Continuous GPS measurements of postglacial adjustment in Fennoscandia 1. Geodetic results. J Geophys Res 107(B8). doi:10.1029/2001JB000400

Johns TC, Durman CF, Banks HT, Roberts MJ, McLaren AJ, Ridley JK, Senior CA, Williams KD, Jones A, Rickard GJ et al (2006) The new Hadley Centre climate model (HadGEM1): Evaluation of coupled simulations. J Clim 19(7):1327-1353

Jungclaus JH, Botzet M, Haak H, Keenlyside N, Luo JJ, Latif M, Marotzke J, Mikolajewicz U, Roeckner E (2006) Ocean circulation and tropical variability in the AOGCM ECHAM5/ MPI-OM. J Clim 19:3952-3972

Katsman CA, Hazeleger W, Drijfhout SS, van Oldenborgh GJ, Burgers G (2008) Climate scenarios of sea level rise for the northeast Atlantic Ocean: a study including the effects of ocean dynamics and gravity changes induced by ice melt. Clim Change. doi:10.1007/s10584-008-9442-9

Katsman CA, Sterl A, Beersma JJ, van den Brink HW, Church JA, Hazeleger W, Kopp RE, Kroon D, Kwadijk J, Lammersen R, Lowe J, Oppenheimer M, Plag H-P, Ridley J, von Storch H, Vaughan DG, Vellinga P, Vermeersen LLA, van de Wal RSW, Weisse R (2011) Exploring high-end scenarios for local sea level rise to develop flood protection strategies for a low-lying deltathe Netherlands as an example. Clim Change 109:617-645. doi:10.1007/s10584-011-0037-5

Kendall RA, Mitrovica JX, Milne GA (2005) On post-glacial sea level: II. Numerical formulation and comparative results on 
spherically symmetric models. Geophys J Int 161(3):679-706. doi:10.1111/j.1365-246X.2005.02553.x

Kierulf HP, Pettersen B, McMillan D, Willis P (2009) The kinematics of Ny-Ålesund from space geodetic data. J Geodyn 48:37-46. doi:10.1016/j.jog.2009.05.002

Kierulf HP, Ouassou M, Simpson MJR, Vestøl O (2013) A continuous velocity field for Norway. J Geod 87(4):337-349. doi:10.1007/s00190-012-0603-2

Kopp RE, Mitrovica JX, Griffies SM, Yin J, Hay CC, Stouffer RJ (2010) The impact of Greenland melt on local sea levels: a partially coupled analysis of dynamic and static equilibrium effects in idealized water-hosing experiments. Climatic Change 103:619-625. doi:10.1007/s10584-010-9935-1

Lambeck K, Smither C, Johnston P (1998) Sea-level change, glacial rebound and mantle viscosity for northern Europe. Geophys J Int 134:102-144

Landerer FW, Jungclaus JH, Marotzke J (2007) Regional dynamic and steric sea level change in response to the IPCC-A1B scenario. J Phys Oceanogr 37:296-312

Lemke P, Ren J, Alley RB, Allison I, Carrasco J, Flato G, Fujii Y,Kaser G, Mote P, Thomas RH, Zhang T (2007) Observations: changes in snow, ice and frozen ground. In: Solomon S, Qin D, Manning M, Chen Z, Marquis M, Averyt KB, Tignor M, Miller HL (eds) Climate change 2007: the physical science basis. Contribution of working group I to the 4th assessment report of the intergovernmental panel on climate change. Cambridge University Press, Cambridge

Lidberg M, Johansson JM, Scherneck H-G, Davis JL (2007) An improved and extended GPS-derived 3D velocity field of the glacial isostatic adjustment (GIA) in Fennoscandia. J Geodyn 81:213-230. doi:10.1007/s00190-006-0102-4

Lidberg M, Johansson JM, Scherneck H-G, Milne GA (2010) Recent results based on continuous GPS observations of the GIA process in Fennoscandia from BIFROST. J Geodyn 50:8-18. doi:10.1016/j.jog.2009.11.010

Lowe JA, Gregory JM (2006) Understanding projections of sea level rise in a Hadley Centre coupled climate model. J Geophys Res C11014. doi:10.1029/2005JC003421

Lowe JA, Howard TP, Pardaens A, Tinker J, Holt J, Wakelin S, Milne G, Leake J, Wolf J, Horsburgh K, Reeder T, Jenkins G, Ridley J, Dye S, Bradley S (2009) UK Climate Projections science report: Marine and coastal projections. Met Office Hadley Centre, Exeter

Lucarini L, Russell GL (2002) Comparison of mean climate trends in the northern hemisphere between National Centers for Environmental Prediction and two atmosphere-ocean model forced runs. J Geophys Res 107(D15):4269. doi:10.1029/2001JD001247

Maximenko N, Niiler P, Centurioni L, Rio M, Melnichenko O, Chambers D, Zlotnicki V, Galperin B (2009) Mean dynamic topography of the ocean derived from satellite and drifting buoy data using three different techniques. J Atmos Ocean Technol 26(9):1910-1919

Meehl GA, Stocker TF, Collins WD, Friedlingstein P, Gaye A, Gregory J, Kitoh A, Knutti R, Murphy J, Noda A, Raper S, Watterson I, Weaver A, Zhao ZC (2007) Global climate projections. In: Solomon S, Qin D, Manning M, Chen Z, Marquis M, Averyt KB, Tignor M, Miller HL (eds), Climate change 2007: the physical science basis. Contribution of working group I to the 4th assessment report of the intergovernmental panel on climate change. Cambridge University Press, Cambridge

Meier MF, Dyurgerov MB, Rick UK, O'Neel S, Pfeffer WT, Anderson RS, Anderson SP, Glazovsky AF (2007) Glaciers dominate eustatic sea-level rise in the twenty-first century. Science 317:1064-1067. doi:10.1126/science.1143906

Milne GA, Mitrovica JX (1998) Postglacial sea-level change on a rotating Earth. Geophys J Int 133:1-19
Milne GA, Davis JL, Mitrovica JX, Scherneck H-G, Johansson JM, Vermeer M, Koivula H (2001) Space-geodetic constraints on glacial isostatic adjustment in Fennoscandia. Science 291:2381-2385. doi:10.1126/science.1057022

Milne GA, Mitrovica JX, Scherneck HG, Davis JL, Johansson JM (2004) Continuous GPS measurements of postglacial adjustment in Fennoscandia: 2. modeling results. J Geophys Res 109(B02412). doi:10.1029/2003JB002619

Milne GA, Gehrels WR, Hughes CW, Tamisiea ME (2009) Identifying the causes for sea-level change. Nat Geosci 2:471-478. doi:10.1038/NGEO544

Min SK, Legutke S, Hense A, Kwon WT (2005) Climatology and internal variability in a 1000 -year control simulation with the coupled climate model ECHO-G. Tellus 57A:605-621

Mitrovica JX, Milne GA (2003) On post-glacial sea level: I. General theory. Geophys J Int 154(2):253-267. doi:10.1046/j.1365246X.2003.01942.x

Mitrovica JX, Davis JL, Shapiro II (1994) A spectral formalism for computing 3-dimensional deformations due to surface loads: 1 . Theory. J Geophys Res 99(B4):7057-7073. doi:10.1029/ 93JB03128

Mitrovica JX, Milne GA, Davis JL (2001a) Glacial isostatic adjustment on a rotating Earth. Geophys J Int 147:562-578. doi:10.1046/j.1365-246x.2001.01550.x

Mitrovica JX, Tamisiea ME, Davis JL, Milne GA (2001b) Recent mass balance of polar ice sheets inferred from patterns of global sea-level change. Nature 409:1026-1029

Mitrovica JX, Gomez N, Clark PU (2009) The sea-level fingerprint of West Antarctic collapse. Science 323:753

Mitrovica JX, Gomez N, Morrow E, Hay C, Latychev K, Tamisiea ME (2011) On the robustness of predictions of sea level fingerprints. Geophys J Int 187:729-742. doi:10.1111/j.1365246X.2011.05090.x

Nakicenovic N, Swart R (eds) (2000) Emission scenarios. Cambridge University Press, Cambridge

Niiler P, Maximenko N, McWilliams J (2003) Dynamically balanced absolute sea level of the global ocean derived from near-surface velocity observations. Geophys Res Lett 30(22):2164

Pardaens AK, Gregory JM, Lowe JA (2011) A model study of factors influencing projected changes in regional sea level over the twenty-first century. Clim Dyn 36:2015-2033. doi:10.1007/ s00382-009-0738-x

Peltier WR (1974) The impulse response of a Maxwell Earth. Rev Geophys Space Phys 12:649-669. doi:10.1029/RG012i004p00649

Pfeffer WT (2011) Land ice and sea level rise: a thirty-year perspective. Oceanogr 24(2):94-111. doi:10.5670/oceanog. 2011.30

Pfeffer WT, Harper J, ONeel S (2008) Kinematic constraints on glacier contributions to twenty-first-century sea-level rise. Science 321:1340-1343

Radić V, Hock R (2010) Regional and global volumes of glaciers derived from statistical upscaling of glacier inventory data. J Geophys Res 115(F01010). doi:10.1029/2009JF001373

Rahmstorf S (2007) A semi-empirical approach to projecting future sea level rise. Science 315:368-370. doi:10.1126/science. 1135456

Richter K., Nilsen JEØ, Drange H (2012) Contributions to sea level variability along the Norwegian coast for 1960-2010, J Geophys Res 117(C05038). doi:10.1029/2011JC007826

Schmidt GA, Ruedy R, Hansen JE, Aleinov I, Bell N, Bauer M, Bauer S, Cairns B, Canuto V, Cheng Y, Del Genio A, Faluvegi G, Friend AD, Hall TM, Hu Y, Kelley M, Kiang NY, Koch D, Lacis AA, Lerner J, Lo KK, Miller RL, Nazarenko L, Oinas V, Perlwitz J, Rind D, Romanou A, Russell GL, Sato M, Shindell DT, Stone PH, Sun S, Tausnev N, Thresher D, Yao MS (2006) Present day atmospheric simulations using GISS ModelE: 
comparison to in situ, satellite and reanalysis data. J Clim 19:153-192

Slangen ABA, Katsman CA, van de Wal RSW, Vermeersen LLA, Riva REM (2012) Towards regional projections of twenty-first century sea-level change based on IPCC SRES scenarios. Clim Dyn 38(5):1191-1209. doi:10.1007/s00382-011-1057-6

Stammer D (2008) Response of the global ocean to Greenland and Antarctic ice melting. J Geophys Res 113(C06022). doi:10.1029/ 2006JC004079

Stammer D, Agarwal N, Herrmann P, Kohl A, Mechoso CR (2011) Response of a coupled ocean-atmosphere model to greenland ice melting. Survey in Geophysics 32(4-5):621-642

Steffen H, Kaufmann G (2005) Glacial isostatic adjustment of Scandinavia and northwestern Europe and the radial viscosity structure of the Earth's mantle. Geophys J Int 163(2):801-812. doi:10.1111/j.1365-246X.2005.02740.x

Steffen H, Wu P (2011) Glacial isostatic adjustment in Fennoscandia a review of data and modeling. J Geodyn 52(3-4):160-2004. doi:10.1016/j.jog.2011.03.002

Tamisiea M (2011) Ongoing glacial isostatic contributions to observations of sea level change. Geophys J Int 186(6): 1036-1044

Tamisiea ME, Mitrovica JX (2011) The moving boundaries of sea level change: understanding the origins of geographic variability. Oceanogr 24(2):24-39. doi:10.5670/oceanog.2011.25

Tushingham AM, Peltier WR (1991) Ice-3G: a new global model of late Pleistocene deglaciation based upon geophysical predictions of post-glacial relative sea level change. J Geophys Res 96:4497-4523. doi:10.1029/90JB01583

Vellinga P, Katsman CA, Sterl A, Beersma JJ, Church JA, Hazeleger W, Kopp RE, Kroon D, Kwadijk J, Lammersen R, Lowe J, Marinova N, Oppenheimer M, Plag HP, Rahmstorf S, Ridley J, von Storch H, Vaughan DG, van der Wal RSW, Weisse R (2008) Exploring high-end climate change scenarios for flood protection of The Netherlands. International scientific assessment carried out at request of the delta committee. Scientific Report WR2009-05. KNMI/Alterra, The Netherlands. Available from http:// www.knmi.nl/bibliotheek/knmipubWR/WR2009-05.pdf
Wada Y, van Beek LPH, van Kempen CM, Reckman JWTM, Vasak S, Bierkens MFP (2010) Global depletion of groundwater resources. Geophys Res Lett. 37(L20402). doi:10.1029/ 2010GL044571

Wada Y, van Beek LPH, Weiland FCS, Chao BF, Wu YH, Bierkens MFP (2012) Past and future contribution of global groundwater depletion to sea-level rise. Geophys Res Lett 39(L09402). doi:10.1029/2012GL051230

Washington WM, Weatherly JW, Meehl GA, Semtner AJ Jr, Bettge T, Craig A, Strand W Jr, Arblaster J, Wayland V, James R, Zhang Y (2000) Parallel climate model (PCM) control and transient simulations. Clim Dyn 16:755-774

Whitehouse P, Latychev K., Milne GA, Mitrovica JX, Kendall R (2006) Impact of 3D Earth structure on Fennoscandian glacial isostatic adjustment: implications for space-geodetic estimates of presentday crustal deformations. Geophys Res Lett 33(13502). doi:10.1029/2006GL026568

Williams SDP (2008) CATS: GPS coordinate time series analysis software. GPS Solutions 12(2):147-153. doi:110.1007/s1029110007-10086-10294

Williams SDP, Bock Y, Fang P, Jamason P, Nikolaidis RM, Prawirodirdjo L, Miller M, Johnson DJ (2004) Error analysis of continuous GPS position time series. J Geophys Res 109:1-19

Wu X, Collilieux X, Altamimi Z, Vermeersen B, Gross R, Fukumori I (2011) Accuracy of the international terrestrial reference frame origin and earth expansion. Geophys Res Lett 38(L13304). doi: $10.1029 / 2011$ GL047450

Yin J, Griffies SM, Stouffer RJ (2010) Spatial variability of sea-level rise in the twenty-first century projections. J Clim 23:4585-4607. doi:10.1175/2010JCLI3533.1

Yongqiang Y, Rucong Y, Xuehong Z, Hailong L (2002) A flexible global coupled climate model. Adv Atmos Sci 19:169-190

Yukimoto S, Noda A (2002) Improvements of the meteorological research institute global ocean-atmosphere coupled GCM (MRICGCM2) and its climate sensitivity. Tech rep 10, NIES, Japan 